M. Köhler, T. Kathrotia, P. Oßwald, M. L. Fischer-Tammer, K. Moshammer, U. Riedel, 1-, 2and 3-pentanol combustion in laminar hydrogen flames - a comparative experimental and modeling study, Combustion and Flame, Volume 162, Issue 9 (2015), 3197-3209 .

The original publication is available at www.elsevier.com

[http://dx.doi.org/10.1016/j.combustflame.2015.05.007] 


\section{1-, 2- and 3-pentanol combustion in laminar hydrogen flames - a comparative experimental and modeling study}

Markus Köhler ${ }^{1}$, Trupti Kathrotia ${ }^{2}$, Patrick Oßwald ${ }^{1}$, Marileen L. Fischer-Tammer ${ }^{1}$, Kai Moshammer $^{3}$, Uwe Riedel ${ }^{1}$

1) Institute of Combustion Technology, German Aerospace Center (DLR), Pfaffenwaldring 38-40, D-70569 Stuttgart, Germany

2) Institute of Combustion Technology for Aerospace Engineering, Stuttgart University, Pfaffenwaldring 38-40, D-70569 Stuttgart, Germany

3) Department of Chemistry, Bielefeld University, Universitätsstraße 25, D-33615 Bielefeld, Germany*

Corresponding author: Patrick Oßwald

German Aerospace Center (DLR)

Pfaffenwaldring 38-40

D-70569 Stuttgart

Germany

Tel: +497116862 265

Email: Patrick.Osswald@dlr.de

* now at Sandia National Laboratories, Combustion Research Facility, Mail Stop 9055, PO Box 969, Livermore, CA 94551-0969 


\begin{abstract}
Oxidation pathways of three different pentanol isomers 1-, 2- and 3-pentanol are investigated using the electron-ionization molecular-beam mass spectrometry (EI-MBMS) technique. New experimental speciation data was obtained from laminar, flat, low-pressure $\mathrm{H}_{2} / \mathrm{O}_{2} / \mathrm{Ar}$ base flames seeded with equal amounts of pre-vaporized 1-, 2- or 3-pentanol. The experimental investigation is supported by kinetic modeling. Here, one single detailed reaction mechanism for the three linear pentanol isomers has been constructed and compared against new and existing experimental data. The model itself was obtained by an open-source reaction model generation software (RMG) and tested against existing ignition delay times, flame speeds and new quantitative experimental results for mole fraction profiles of major and intermediate species.

The overall discussion of individual species profiles is guided by the model-based reaction flow analysis focusing on the initial steps of the fuel destruction paths for the three pentanols down to C3-hydrocarbon species. Therefore, the reaction pathways for the initial fuel destruction steps are shown and analyzed using combined experimental and predicted results. Analysis is performed by means of secondary decay products for each of the three pentanols. The kinetic reaction model was successfully tested versus available ignition delay time and laminar flame speed data. Comparisons against 23 new quantitative species profiles are presented for each of the pentanol doped flames. In general, a good predictive capability of the detailed model can be noted for all three investigated straight-chain pentanols regarding the mole fraction profiles of major and intermediate species.
\end{abstract}

\title{
Keywords
}

Laminar flame, pentanol combustion chemistry, biofuel, molecular-beam mass spectrometry (MBMS), speciation 


\section{Introduction}

In response to the global concerns for greenhouse gas emissions $\left(\mathrm{CO}_{2}\right)$ and energy sustainability, biofuels have gained interest because of their renewability, $\mathrm{CO}_{2}$-saving benefits, reduction of pollutant formation (i.e. PAH and soot), and compatibility with current engine designs [1-3].

Alcohols for biofuel combustion and as an energy storage medium have become a strong public topic over the last decade [4] accompanied by numerous fundamental studies on combustion. A comprehensive overview of recent results on alcohol combustion kinetics is given by Sarathy et al. [5] as an initial source of references and guidance regarding the present status of alcohol combustion experiments and models.

Recently, C4-C6 alcohols are under investigation for application in the transport sector (including aviation), especially if produced from non-edible feedstock. They provide advantages over ethanol as they feature higher energy density, reduced hygroscopic and therefore reduced corrosive behavior. These striking findings are promising characteristics for possible future applications, while avoiding the controversial discussion on biofuel sustainability. However, mass availability of higher alcohols is currently far from the wellestablished commercial ethanol production, and novel cost- and energy-efficient synthesis of larger alcohols from biological sources are currently under investigation [6, 7].

Fundamental combustion data for larger alcohols (C5 and higher) are steadily growing over the past 3 years. Initial studies in HCCI engines with iso-pentanol (3-methyl-1-butanol) by Yang et al. [8] showed promising characteristic engine performance. These initial experimental results were used by Tsujimura et al. [9], who developed a related detailed kinetic mechanism. Recent investigations of pentanol blends in a diesel engine from CamposFernandez et al. [10] and Wei et al. [11] confirm the overall applicability of pentanols and emphasize on very promising trends in reducing mass concentration and particulate number concentrations.

Fundamental speciation data were measured by Togbé et al. [12], who reported concentration profiles of stable species for 1-pentanol oxidation in a jet-stirred reactor (JSR) at 10 atm and laminar flame speeds for 1-pentanol/air mixtures at $1 \mathrm{~atm}$. The results were subsequently modeled, showing good agreement with the experiment. Dayma et al. [13] followed with combining experimental and kinetic studies for iso-pentanol oxidation in a JSR at 10 bar.

The ignition behavior was studied by Tang et al. [14], who presented shock-tube ignition delay times of the three primary alcohols 1-pentanol, iso-pentanol and 2-methyl-1-butanol and 
modeled with a mechanism from Dagaut et al. [12, 13]. A lesser reactivity for iso-pentanol with respect to 1-pentanol was reported from their data. Heufer et al. [15] extended their 1butanol model to 1-pentanol using measured auto-ignition delay times for 1-pentanol in a shock tube and a rapid compression machine (RCM).

A premixed laminar flame speed study on 2-methyl-1-butanol was presented by Li et al. [16] and calculation of pressure and temperature-dependent rate coefficients for the thermal decomposition of iso-pentanol was reported by Zhao and co-workers [17]. First photoionization mass spectrometry data for low-temperature oxidation mechanisms of isopentanol are available from Welz and co-workers [18], who emphasize the importance of isopentanal and enols.

Sarathy et al. [19] provided a detailed chemical model for iso-pentanol based on quantum chemical calculations from [18] and validated it against experimental data including ignition delay times, species information from JSR experiments, premixed laminar flame speeds, and non-premixed extinction strain rates from counter-flow flames [19]. Recently, a flame study of 2-methylbutanol by using flame-sampling molecular-beam mass spectrometry was presented by Lucassen et al. [20] accompanied by modeling from KAUST closing the gap to the available 2-methylbutanol data sets. Additional pyrolysis mass spectrometric studies with modeling were performed by Zhang et al. [21], while JSR experimental and model studies are reported from Serinyel et al. [22] for 2-methylbutanol. The focus of the latter studies is on the branched pentanol isomers, while experimental data for 1-, 2- and 3-pentanol is limited.

In general, the analysis of such a variety of potential alternative fuels requires new experimental and modeling development strategies. Recent reports on innovative experiments like the iPEPICO approach $[23,24]$ in combustion environments have proven to be promising tools for investigating complex chemical reaction networks. Also, the kinetic modeling of such complex fuel systems is highly demanding and takes traditional methods to their limits. For a long time, the accepted approach to mechanism development has been based on hierarchy, starting from smaller molecules such as hydrogen as fuel and adding C1-C2 and larger hydrocarbons. Regarding new alternative fuels, the development of purely hierarchic mechanisms becomes more challenging, e.g. due to the high numbers of isomers from the larger fuel molecules. In such cases, computer-based generation tools have shown a great potential.

Here, we present the first comparative flame study for 1-, 2- and 3-pentanol with experimental speciation data and kinetic modeling. The alcohol combustion chemistry is investigated in 
pentanol-doped hydrogen flames. Speciation is performed by electron ionization molecularbeam mass spectrometry (EI-MBMS) with subsequent quantification.

The present model was constructed by using the Reaction Mechanism Generator RMG [25] that provides a single detailed mechanism for all linear pentanol isomers. The mechanism is compared with ignition delay time data from Tang et al. [14] and laminar flame speeds from $\mathrm{Li}$ et al. [16]. Further comparison with the new flame measurements presented here demonstrates the ability of the mechanism to predict all three pentanol fuels well with special focus on the initial destruction pathway. Finally, we conclude by highlighting experimental data that indicate the presence of double oxygenated species. 


\section{Experimental method}

\subsection{Flames and burner}

Doped hydrogen flames are used to investigate the oxidation chemistry of different pentanol isomers. The $\mathrm{H}_{2} / \mathrm{O}_{2} / \mathrm{Ar}$ low-pressure (20 mbar) base flame is seeded with 1-, 2-, and 3pentanol. The premixed flames were stabilized on a $\varnothing=64 \mathrm{~mm}$ McKenna type burner with a total flow rate of $4.55 \mathrm{slm}$ (standard liter per minute). The molar composition of each flame is: $0.14(18) \mathrm{O}_{2}, 0.35(39) \mathrm{H}_{2}, 0.49$ (96) $\mathrm{Ar}$ and 0.0047 of the respective pentanol. The resulting stoichiometry is $\phi=1.5$ and the cold gas $(300 \mathrm{~K}$ ) velocity is $131 \mathrm{~cm} / \mathrm{s}$.

The liquid pentanol is vaporized and added to the premixed gas stream by a vaporizer system optimized for small amounts of liquid fuel [26] by reducing volume and lengths to a minimum. The vaporizer system itself consists of a heated $\left(150^{\circ} \mathrm{C}\right)$ tube $(\varnothing=10 \mathrm{~mm}$, length $150 \mathrm{~mm}$ ) filled with mineral wool. Approx. 50\% of the Ar stream is fed through the vaporizer to ensure stable evaporation. Liquid fuels are pumped by a syringe pump (Protea Biosciences, PM-1000) equipped with a $10 \mathrm{ml}$ syringe and injected through a septum to the vaporizer. Pressure inside the vaporizer is regulated by a needle valve at the outlet and set to 1050 mbar. Required liquid flow rates are 102.8-104.0 $\mu \mathrm{l} / \mathrm{min}$ with respect to the individual density of each pentanol.

\subsection{Molecular-beam mass spectrometry (MBMS)}

Measurements were performed using the Bielefeld molecular-beam mass spectrometry (MBMS) system described elsewhere [27, 28]. The flat flame burner is mounted on a translational stage inside the low pressure chamber and can be moved with high relative precision while the absolute uncertainty in the burner-to-cone distance is less than $0.3 \mathrm{~mm}$. Gases are withdrawn by a quartz cone from a distinct position at the centerline of the flat flame via a $500 \mu \mathrm{m}$ orifice at the nozzle tip and transferred into a molecular beam (two stage pumping; $10^{-4}$ and $10^{-6} \mathrm{mbar}$ ). Due to the rapid expansion, reactions are quenched immediately and the molecular composition of the sample is conserved. The molecular beam is guided to the ion source of an electron impact (EI) time-of-flight mass spectrometer and species are detected by their exact mass. The performance of the system allows for the determination of the elemental composition $(\mathrm{C} / \mathrm{H} / \mathrm{O})$ of stable and radical species present in the flame down to concentrations in the ppm regime. Signals are recorded as function of the burner-to-cone distance $(h$ ) for two different ionization energies of 10.3 and $14.9 \mathrm{eV}$ (values indicate the actual peak value of the electron energy distribution). 
Quantitative signal analysis is obtained following procedures outlined in [23, 27, 29]. Major species (products, reactants, dilutant) are calibrated by an internal calibration strategy relying on the $\mathrm{C}$-, $\mathrm{H}$-, and O-balances and the determination of the $\mathrm{CO} / \mathrm{CO}_{2}$ exhaust gas ratio. This strategy was primarily developed for rich hydrocarbon flames. However, modifications are necessary because of the $\mathrm{H}_{2}$ base flame used herein is providing extraordinarily high fractions of $\mathrm{H}$ radicals (up to $10 \%$ ). This value cannot be neglected in the element balances. Thus, the equations for partial equilibrium [30] of $\mathrm{H}$ and $\mathrm{OH}$ and the ratio of $\mathrm{H}_{2} / \mathrm{O}_{2}$ have been included in the equation system describing the exhaust gas composition (see supplemental material for details). The experimental determination of the $\mathrm{H}_{2} / \mathrm{O}_{2}$ ratio failed due to the low $\mathrm{O}_{2}$ concentration in the exhaust. However, even though the measured remaining $\mathrm{O}_{2}$ concentrations scatter by a factor of three between the flames of this series, the order of magnitude predicted by the kinetic model is confirmed and thus values for the $\mathrm{H}_{2} / \mathrm{O}_{2}$ ratio are adopted from the model calculation. Equilibrium constants are obtained via GasEq [31] from the Goos-Burcat database [32]. Due to the limited number of available oxygenated calibration substances a systematic approach was chosen for determining calibration factors for some of the intermediate species presented herein. The signal simulation procedure $[27,29]$ is based on the convolution of a respective ionization cross section and the known (calibrated) energy distribution of the electrons in order to simulate the signal of a calibration measurement. The required individual ionization cross sections are obtained from additivity rules [33] based on the elemental composition of a species. This theory provides a reliable estimate of the ionization cross section $(\sigma)$ at its plateau $(\approx 70 \mathrm{eV})$ while the near-threshold slope (xs) of the cross section is needed to obtain a calibration factor (see [27]). Here, this value is obtained by linear extrapolation from the ionization threshold (IP) to the apex which was found at $50 \mathrm{eV}$ for most species:

$$
x S_{i}=\frac{\sigma_{i}(70 \mathrm{eV})}{50-I P_{i}}
$$

The procedure was tested for 13 species with known xs and deviations are less than $30 \%$ for most hydrocarbon and oxygenated species. The outlined calibration approach was applied for most species where a direct calibration via cold gas measurements was not achievable. Table 1 provides an assignment of applied calibration strategies to the respective species. Beside the outlined extrapolation based on the additivity rules of Fitch and Sauter [33] ("F\&S”), the convolution of literature ionization cross sections [34] (“Conv.”) as well as the relative 
ionization cross section method [27, 35] ("RICS") where applied for calibration of individual species. Methods are selected based on the available species data and reference measurements to provide the most reliable calibration. Ionization thresholds (IP) are taken from NIST webbook [36] according to the assumed (“Calibrated as”) species. A detailed description of the procedures is reported in the supplemental information of [27]. Discrepancy of the calibration factors, obtained by the assumption of different isomers (i.e. different IP), are dependent on the individual species due to the applied electron energy and the respective IP values. Typically, the deviation is less than the absolute experimental uncertainty associated with the estimation procedure. Thus, just a single isomer is assumed even if complex mixtures are present in the flame. For example, the values of the obtained calibration factors for the $\mathrm{C}_{4} \mathrm{H}_{8} \mathrm{O}$ isomers butenal and butanone differ by $35 \%$.

Experimental mole fraction and temperature profiles are available as supplemental material. In addition to the three conditions containing the linear 1-, 2- and 3-pentanol isomers discussed herein, mole fraction profiles of similar doped 3-methyl-1-pentanol (isopentanol) and 3-methyl-2-pentanol flames are provided. Since the present work is focused on the linear isomers, not each measured signal was evaluated for these branched fuels. Further information is available from the authors on demand.

\subsection{Experimental temperature determination}

Temperature is a crucial parameter for kinetic modeling and good results were obtained, when disturbed temperature profiles were used as input for modeling MBMS data [23, 37-40]. Using a disturbed temperature profile cancels the need of shifting the simulated data and offers better model validation regarding peak positions and profile shapes. The temperature profile can be extracted from the sampling rate in MBMS experiments, i.e. the first-stage pressure or the inert gas signal, see $[41,42]$. The procedure, where the profile is derived from the argon mole fraction, provides a relative profile, and a calibration temperature is needed.

This calibration temperature was adopted from laser-induced fluorescence (LIF) of the $\mathrm{OH}$ radical in a similar doped hydrogen flame at 30 mbar; all relative temperature profiles for the flames of the hydrogen doped series are found to be similar due to the minor doping amount. Thus, the value may be adopted for each of the investigated flames.

The applied laser system is described in [43] with modified detection system, so only a brief description is given here. The optical setup consists of a frequency-doubled flash-lamp pumped Nd:YAG laser (Spectra Physics PIV-400-10) pumping a tunable dye laser (Sirah 
PRSC-G-24-EG) with frequency-doubling unit to allow for UV excitation at $10 \mathrm{~Hz}$. The pulse energies at the measuring location were approximately $0.3 \mathrm{~mJ}$ to minimize potential saturation effects with a bandwidth of about $0.4 \mathrm{~cm}^{-1}$ and a pulse duration of 7 ns. Excitation of $\mathrm{OH}$ was performed in the range of $282.5 \mathrm{~nm}$ to $282.8 \mathrm{~nm}$, capturing the $\mathrm{Q}_{1}(5), \mathrm{R}_{1}(14), \mathrm{R}_{2}(13)$ and $\mathrm{P}_{1}(2)$ lines of the $\mathrm{A}^{2} \Sigma-\mathrm{X}^{2} \Pi(1,0)$ transition with a scan rate of $5 \times 10^{-4} \mathrm{~nm} / \mathrm{s}$. Wavelength tuning of the dye laser was checked with simulations by LIFBASE Version 2.0.6 [31], which was likewise used for interpretations and line selection. The range was found to be sensitive to temperatures above $800 \mathrm{~K}$. The laser beam was formed into a circular shape with approx. 1 $\mathrm{mm}$ diameter using a pinhole; excitation of $\mathrm{OH}$ was performed at $25 \mathrm{~mm}$ height above burner in the post flame region.

The excited fluorescence signal was collected using a two UV lens optic ( $\mathrm{f}_{1}=500 \mathrm{~mm}$, $\mathrm{f}_{2}=150 \mathrm{~mm}$, Cerco, AR-coated). Signals are detected with a photomultiplier (Hamamatsu R928) and analyzed with a $350 \mathrm{MHz}$ digital oscilloscope (Agilent Technologies DSO 7034B). Scattering at $283 \mathrm{~nm}$ was blocked using a high transmission (>80\% at $310 \mathrm{~nm}$, bandwidth 20 $\mathrm{nm}$ ) bandpass interference filter (Custom fabrication - Laser Components GmbH) and a color glass filter (1 mm thick WG305, Schott glass). Energy monitoring and signal normalization to the laser energy was performed using a power meter (Gentec Duo). Concerning the accuracy of the temperature measurements, we estimate the uncertainty from the quality of the Boltzmann plot to be $120 \mathrm{~K}$ in the post flame zone. The adiabatic flame temperature for the doped flame used for LIF measurements is $2430 \mathrm{~K}$, whereas the adiabatic flame temperature for the 2-pentanol case is slightly lower at $2397 \mathrm{~K}$. Both values are very similar, underlining the similarity of both flames.

Finally, the measured temperature obtained from OH-LIF in the post flame region is $1150 \mathrm{~K}$. Remarkably, this is a fairly low value in contrast to typical low-pressure flames especially when the adiabatic flame temperature of $2397 \mathrm{~K}$ is considered. However, a brief literature review confirms this low value for comparable low-pressure, premixed hydrogen flames: Vandooren et al. [44] report $1180 \mathrm{~K}\left(\mathrm{H}_{2} / \mathrm{O}_{2} / \mathrm{Ar}, \phi=1.91,47 \mathrm{mbar}\right)$ measured by thermocouple, Pauwels et al. [45] $980 \mathrm{~K}\left(\mathrm{H}_{2} / \mathrm{O}_{2} / \mathrm{Ar}, \phi=1.5\right.$, 33 mbar) measured by OH-LIF and thermocouple, Lawitzki et al. [46] measured $1200 \mathrm{~K}\left(\mathrm{H}_{2} / \mathrm{O}_{2} / \mathrm{N}_{2}, \phi=1.4,95\right.$ mbar) measured by CARS or other reports [47-50], all around $1100 \mathrm{~K}$ for similar flame conditions. The huge discrepancy to the adiabatic flame temperature may be assigned to a) heat loss through the burner surface, which is remarkably high in these flames and b) the extraordinary 
high $\mathrm{H}$-atom fraction which does not reach thermodynamic equilibrium. Each effect accounts roughly for $400 \mathrm{~K}$ lower flame temperature.

\section{Computational method}

\subsection{Kinetic model generation}

In this work, the detailed reaction mechanism for 1-, 2- and 3-pentanol has been constructed using an open-source rule-based reaction model generation software (RMG) developed at MIT [25]. The reaction mechanism is enlarged iteratively using the rate-based algorithm by Susnow et al. [51]. The reactions are generated by comparing each possible pair of molecules against the 34 incorporated reaction family templates in the database. Reaction rates are estimated subsequently and reactions are filtered based on specified criteria.

In RMG, the rate-based reaction system is typically built upon a user specific "seed" mechanism including smaller hydrocarbons. For the seed mechanism, besides the reactions and the corresponding rate constants, information about the molecular structure of each species in the base mechanism needs to be supplied in a RMG specific format. For a RMG model generation, it is recommended to use broadly validated base chemistry of smaller alkanes, where the reaction rates are based on established literature data. The RMG input conditions used in present work for the generation of mechanism are:

- Temperature range: 1000 - $2500 \mathrm{~K}$ in steps of $500 \mathrm{~K}$. Smaller steps do not lead to a more detailed reaction mechanism. This observation only applies to the specified temperature range, where no low temperature chemistry is contributing significantly.

- Pressures: 0.01, 1, and 10 bar. Only for the reactions of pentanol chemistry generated by RMG, the pressure-dependence is taken into account by the RMG generation procedure.

- The pressure dependence of rate constants is estimated using the modified strong collision approach of Chang et al. [52] for a temperature range of $300-2500 \mathrm{~K}$ and a pressure range of $0.01-100$ bar. This is an optional feature of RMG allowing the user to obtain pressure dependent reaction rates.

- The termination criterion for the mechanism generation process is set to $90 \%$ fuel conversion and an error tolerance of 0.004 .

The mechanism is generated based on the given range of temperature and pressures until the user defined tolerance criteria are met for the above mentioned target fuel conversion. The 
thermochemistry of the RMG generated species are estimated using Benson's group additivity method [53] and the transport properties such as Lennard-Jones-parameters estimation are implemented in RMG using empirical correlations based on critical properties database [54].

The basic chemistry (i.e. the "seed mechanism") of smaller hydrocarbons (C1-C4) was adapted from the high temperature USC mechanism, version-II [55]. Few reactions of USC-II were updated to include recent updates in rate coefficients. This insertion in USC-II is intended to improve the overall performance of base mechanism before its use in RMG.

The $\mathrm{H}_{2} / \mathrm{O}_{2}$-mechanism by Burke et al. [56], which is a revised version of the Li et al. mechanism [57], is considered in present work. Their updates include the recent assessment of rate coefficients for broader temperature and pressure range with an emphasis on fall-off treatment of sensitive reactions.

Comparisons between the $\mathrm{H}_{2} / \mathrm{O}_{2}$-mechanism from Burke et al. and USC-II mechanism are shown in their supplementary material for species time-histories, ignition time, mass burning rates and flame speeds over a wide range of pressures and temperatures. For most test cases, better or equal agreement with experimental data is achieved by the Burke et al. model, especially for high-pressure and/or flame targets at diluted conditions [56]. Merchant et al. [58] showed in their publication on combustion and pyrolysis of iso-butanol, that the "change in predictions to the iso-butanol experiment caused by the substitution of Burke et al. model is within the various errors ranges associated with the simulation methods and the experimental measurements."

Improved agreement by the substitution of the $\mathrm{H}_{2} / \mathrm{O}_{2}$-system by the Burke et al. model compared to USC-II mechanism is observed for the comparison of the flame speed of the nbutane/ $\mathrm{O}_{2} / \mathrm{N}_{2}$ flame measured by Davis and Law [59] for equivalence ratios of $0.7<\Phi<1.3$. However, similar results are achieved by the same substitution for the ignition delay time of n-butane/air at 1.2 atm measured by Zhang et al. [60]. These updates especially lead to the improved agreement between experiments and simulated predictions in the diluted, highpressure flames. The thermodynamic data of all species in the Burke et al. mechanism and the USC-II mechanisms are supplied as thermo libraries. The transport data of the USC-II mechanism is supplied as primary transport library for "seed" species.

In addition, the following modification has been made to the base USC-II mechanism in order to obtain validity of the mechanism for a wider pressure range. These few reactions that have been updated by recent revised rate coefficients are, 
- The rate for the reaction $\mathrm{C}_{2} \mathrm{H}_{4}+\mathrm{CH}_{3}=\mathrm{nC}_{3} \mathrm{H}_{7}$ has been changed based on the pressuredependent rate coefficients recommended by Miller and Klippenstein [61] in the pressure range of 0.001 to 101 bar and at infinite pressure $k_{\text {inf }}$.

- The rate for the reaction $\mathrm{C}_{3} \mathrm{H}_{6}+\mathrm{H}=\mathrm{CH}_{3}+\mathrm{C}_{2} \mathrm{H}_{4}$ has been changed based on the pressure-dependent rate coefficients recommended by Miller and Klippenstein [61]. These rates are valid in the pressure range of 0 to 101 bar.

Additionally, the USC-II mechanism has been rewritten in this work to take wider pressure range into consideration. In the original USC-II mechanism, few pressure dependent reactions are supplied as separate reactions at different pressures. These reactions are rewritten into the pressure-dependent PLOG [62] format enabling the pressure fall-off effect by a fitting function instead of discrete points. Once the standard base mechanism is obtained, no further modification had been allowed during model generation.

Overall, the generated mechanism for all three isomers results in a single mechanism consisting of 225 species and 24526 reactions. Note, that lumping of isomers is not considered during the mechanism generation, resulting in this large size of the mechanism. However, this provides a high level of details, and their reduction is beyond the scope of the present work.

The reaction model of all three isomers discussed in this work represents high-temperature chemistry. Some di- and tri-oxygenated species are generated by RMG due to broader input pressure conditions, and therefore these species important at low temperature conditions are removed from the mechanism to restrict the model for high temperature reactions. This is done manually as its formation cannot be restricted by any RMG parameter. However, future extension of the model for low-temperature conditions is intended. No further modifications are made to the RMG generated model of the three pentanols.

Finally, all generated species that satisfy the given input and termination criteria, are selected within the RMG process. Subsequently, all the corresponding generated reactions form the final mechanism presented here. The major reaction types at high temperatures are $\mathrm{H}$-atom abstraction reactions. Due to the rule-based generation, the $\mathrm{H}$-abstraction reactions of given species is generated with all species as abstracting species in the mechanism. Only reactions with major abstracting species such as $\mathrm{H}, \mathrm{OH}, \mathrm{HO}_{2}, \mathrm{H}_{2} \mathrm{O}_{2}, \mathrm{CH}_{3}$ etc. are considered relevant, while all other reactions have no major influence on the prediction of the combustion 
behavior. Therefore, removal of such reactions can help to reduce the model, in our case by approximately 7000 reactions, which might be important in case of larger combustion model applications. The reactions of the generated mechanism, irrespective of the condition studied, include fuel decomposition (unimolecular) as well as $\mathrm{H}$-abstraction reactions leading to alkoxy radicals; the radical decomposition $\beta$-scission reactions by $\mathrm{C}-\mathrm{C}, \mathrm{C}-\mathrm{H}$, and $\mathrm{C}-\mathrm{O}$ bond scission lead to various unsaturated alcohols and enols, inter-isomerization of radical isomers and enol decomposition reactions.

\subsection{Pentanol reaction model}

The three pentanols studied here have a similar C5-backbone structure with the difference of the location of the OH-group, which influences the reactivity of the respective pentanol molecules. The reaction rate of the different pentanol isomers varies depending on the bond dissociation energies of the different bonds and their position to the hydroxyl group.

The high-temperature reactions related to the pentanol sub-model can be described by the reaction classes for alcohol oxidation summarized recently by Sarathy et al. [5]. The reactions of all three pentanols in this work include each of these reaction classes with an exception of keto-enol isomerization reaction catalyzed by formic acid. The production of formic acid was found to be negligible during the mechanism generation and the species is thus not present in the mechanism. However, the H-atom assisted isomerization of enol to ketones/aldehydes is included in the mechanism.

The present kinetic model is provided with the supplementary material of this paper. The detailed reaction mechanism including the thermochemistry data as well as the transport data file are available in CHEMKIN format. Additionally, a list of species and its structures for the present reaction mechanism is provided to guide on species identification.

\subsection{Comparison to existing models}

Until now, no reaction models for 2- and 3-pentanols are published, and the mechanisms of 1pentanol are fairly known. These are recent models from Sarathy et al. [19] as well as from Dagaut's group [12].

In detail, the 1-pentanol model of Dagaut and co-workers [12] does not include unsaturated alcohols as these species were not detected in their diffusion flame experiment and considered minor species. Additionally, JSR experiments show comparable findings in similar studies of 
n-butanol [63]. Thus, their mechanism does not include radical decomposition reactions of enols and enol radicals as well as enol-keto isomerization reactions.

In comparison to Dagaut's model, the 1-pentanol reaction mechanism of Sarathy et al. [19] includes all the reactions listed above. Therefore, the reaction mechanism of the present work is comparable with respect to the 1-pentanol sub-model of Sarathy et al. [19]. However, especially for the minor intermediates, there are few differences between the two mechanisms, while the simulated species profiles by both mechanisms are found to be similar for most species. A brief discussion is presented in section 4.3.1 accompanied by additional comparing figures in the supplemental material.

\subsection{Combustion modeling}

Reaction kinetics of the laminar premixed burner-stabilized one-dimensional flames, laminar flame speeds, and zero-dimensional (0-D) homogeneous closed reactor model for predicting ignition delay times presented here, were calculated using Chemical WorkBench [64].

Standard input parameters to the burner-stabilized flame simulations are the fuel-oxidizer composition, initial pressure, and known mass flow. The measured experimental temperature profiles are used as an input parameter to the calculations. The flames are calculated considering thermal diffusion using a multi-component transport model.

The simulations of the adiabatic freely propagating flames to calculate laminar flame speeds require the initial flame conditions i.e. fuel-oxidizer composition, temperature, and pressure. Ignition delay times are calculated based on a 0-D homogeneous constant volume reactor model with the initial mixture composition and the initial temperature and pressure behind the reflected shock wave as input. The temperature is calculated for adiabatic conditions. The ignition delay times are determined from the onset of $\mathrm{CH}$ chemiluminescence profiles.

\section{Results and discussion}

In the following paragraphs the model capability is presented starting with general combustion properties, i.e. the ignition delay times, flame speed, temperature behavior and major species profiles for 1-, 2- and 3-pentanol. The subsequent discussion focuses on respective fuel destruction reactions of the three pentanols, which are explored in great detail along the individual species profiles. Interpretation is guided by the model-based reaction flow analysis and focuses on the initial steps of the fuel destruction paths for the three 
pentanols. Conclusively, further data for combustion intermediates are discussed and new species are presented.

\subsection{Ignition delay times, flame speeds and temperature profiles}

In addition to the flame comparison of the current work, the reaction model is also compared with global parameters of flame speed and ignition delay times against measurements from literature to emphasize on the general usability.

The proposed model is first compared against high temperature shock tube data from Tang et al. [14] for 1-pentanol. Ignition delay time measurements for both other pentanols are, to the best of our knowledge, not available. The data from Tang et al. was acquired for 5 conditions over a temperature range of $1100-1500 \mathrm{~K}$, equivalence ratio of $0.25,0.5$ and 1 , pressures at 1 atm and 2.6 atm and $\mathrm{O}_{2}$ concentration in the fuel $/ \mathrm{O}_{2} / \mathrm{Ar}$ mixtures varying from $3.75 \%$ to $15 \%$. Figure 1 (left) shows the experimental data along with computed ignition delay times for 5 conditions. The model has a reasonable agreement with the experimental data and is capable of properly reproducing the experimental dependency of the ignition behavior for varying stoichiometry and pressure.

While agreement for the higher temperature regime is good, the model results give a slight over-prediction in the relatively lower temperature regime. Tang et al. found the same for their model concluding in uncertainties in low temperature basic chemistry reactions. However, it should be noted that only three data points are available in this regime. Generally, the performance of the model is found to be fairly good for the presented cases and trends are captured satisfactorily.

The flame speed of all three pentanols studied in this work was measured by Li et al. [16]. They measured laminar flame speed of 1-, 2- and 3-pentanol-air mixtures on a variety of pressures and initial temperatures. Figure 1 (right) presents the comparison of flame speeds measured at $433 \mathrm{~K}$ preheat temperature and 1 bar pressure in the stoichiometry range of 0.6 to 1.8. The flame speed of 2-pentanol is lower than that of the other two flames. In all three cases the predicted laminar flame speed is in excellent agreement with the experimental measurements.

Figure 2 shows the measured experimental temperature profile with the temperature profiles obtained from solved energy balance calculation for the 1-, 2- and 3-pentanol. The temperature profiles calulated from the energy balance solution are almost identical as expected. For the calculation, the boundary conditions of stabilized flame apply at the burner 
surface where heat flux and small species diffusion to the boundary is taken into account. Note, that the experimental data represents a disturbed profile due to the presence of the quartz cone, while the solution of the energy balance represents the undisturbed system. The disturbed profile is shifted downstream as typically seen for the disturbed case [65]. Additionally, the gas temperatures are about $150 \mathrm{~K}$ lower than the undisturbed prediction. Since the disturbed profile was calibrated using the LIF exhaust gas value (measured in the undisturbed flame), this deviation may not be attributed to the disturbance by the cone. However, these findings are still in agreement with the elaborate studies of Struckmeier et al. [41] and Hartlieb et al. [66]. Both demonstrated that the influence of the quartz nozzle leads to a downstream shift in temperature profile as well as cooling of the exhaust gas temperature up to a couple of $100 \mathrm{~K}$.

Even through no complete undisturbed temperature profile is available for this doped hydrogen flame series, this finding gives additional evidence for a proper treatment of the temperature conditions. The temperature uncertainty of $120 \mathrm{~K}$ is estimated in post flame region. Other than product species, none of the species survive in post flame region, so the effect of temperature uncertainty can be seen in the post flame zone of product species profiles $\left(\mathrm{H}_{2} \mathrm{O}, \mathrm{CO}, \mathrm{CO}_{2}\right)$. Since the measured temperature are input parameters to the model calculations, the deviation of the model results for the given maximum $120 \mathrm{~K}$ in temperature can lead to an uncertainty in the prediction of $\mathrm{H}_{2} \mathrm{O}, \mathrm{CO}, \mathrm{CO}_{2}$ and is found to be less than $10 \%$ for all three pentanol isomers.

\subsection{Major species}

Major species mole fractions from the EI-MBMS experiment are reported in Fig. 3 and compared with the modeling results for all three flames using the same detailed model. The major compounds of the base flame i.e. $\mathrm{H}_{2}, \mathrm{H}_{2} \mathrm{O}, \mathrm{O}_{2}$ and $\mathrm{Ar}$ as well as the seeded pentanols with their reaction products $\mathrm{CO}$ and $\mathrm{CO}_{2}$ are predicted satisfactorily by the model. As expected, no difference of the major flame structure is observed among the three flames.

Clearly, the model results match the major species profiles within the expected uncertainties. A good predictive capability for the major species profiles can be noted for 1-, 2- and 3pentanol that is valid for the profile shapes as well as for the exhaust gas concentrations. Some minor deviations of the profile shapes are seen in the water and hydrogen profiles along with a marginal overestimation of $\mathrm{CO}$ by the model in all three cases. The conversion $\mathrm{H}_{2}$ to $\mathrm{H}_{2} \mathrm{O}$ appears to be somewhat too slow in the model prediction. 
In combination with the previous comparison of ignition delay times and flame speeds, a reasonable description of the global flame chemistry can be reported here for all linear pentanols, while this analysis demonstrates the robustness of the model even for the harsh hydrogen heavy conditions presented here.

\subsection{Major fuel destruction pathways}

In order to analyze the comparisons between model predictions and experimental measurements for the 1-, 2- and 3-pentanol, we follow the main decomposition paths moving from the heavier primary species to lower C4- and C3-hydrocarbon species and identify key role species alongside.

The reaction pathway diagram for the 1-, 2- and 3-pentanol oxidation based on the analysis of the presented model for all three pentanol doped hydrogen flames is shown in Fig. 4. The figure illustrates the main destruction channels for the three pentanols at the instant of $20 \%$ fuel consumption. The rate-of-production analysis, based on local rates along the flame, allows evaluating the overall contributions of the different consumption paths.

In general, flame-typical abstraction of $\mathrm{H}$-atoms by small radicals $(\mathrm{H}, \mathrm{OH})$ is identified to be the primary fuel consumption reaction, while other reaction types are found of minor importance for the present conditions. However, for reasons of clarity, only the major contributors are shown in Fig. 4 alongside the significant stable species. The only exceptions are the fuel radicals and the $\mathrm{C}_{4} \mathrm{H}_{9}$ radical, since they serve as a major role in the main destruction pathway for all investigated pentanols. Note, that typical pathways shown in Fig. 4 are consecutive $\mathrm{H}$-abstraction followed by the scission of a $\mathrm{C}-\mathrm{H}, \mathrm{C}-\mathrm{C}$ or $\mathrm{C}-\mathrm{O}$ bond in $\beta$ position i.e.:

$$
\mathrm{R}-\mathrm{CH}_{2}-\mathrm{CH}(\mathrm{X})-\mathrm{R}^{\prime}+\mathrm{H} / \mathrm{OH} \rightarrow \mathrm{R}-\dot{\mathrm{C}} \mathrm{H}-\mathrm{CH}(\mathrm{X})-\mathrm{R}^{\prime}+\mathrm{H}_{2} / \mathrm{H}_{2} \mathrm{O} \rightarrow \mathrm{R}-\mathrm{CH}=\mathrm{CH}-\mathrm{R}^{\prime}+\mathrm{X} \bullet
$$

with $\mathrm{X}=\mathrm{H}, \mathrm{R}, \mathrm{OH}, \mathrm{OR}$.

Most reactions follow this sequence. Deviant reaction sequences, however, are mentioned in the text.

Considering the structure of the individual pentanol $\left(\mathrm{C}_{5} \mathrm{H}_{11} \mathrm{OH}\right)$ molecule, $\mathrm{H}$-abstraction can take place at the $\alpha-, \beta-, \gamma-, \delta-$ and $\varepsilon$-carbon position with respect to the $\mathrm{OH}$ moiety. Structures of the resulting radicals are given in Fig. 4. Abstraction of the hydroxyl-H (i.e. from the $\mathrm{OH}$-moiety) as well as from the terminal $\mathrm{CH}_{3}$ groups in 1- and 2-pentanol 
destruction was found to be negligible during the rule-based generation of the mechanism due to the high bond energies.

The measured mole fractions of the initial $\mathrm{C}_{5} \mathrm{H}_{10} \mathrm{OH}$ radicals are shown Fig. 5 (top, left). Notably, evaluation of the fuel radical was possible for the present measurements even though a high degree of scatter must be accepted due to the low concentrations. Since the EI-MBMS technique does not provide the resolution of isomeric structures, comparison to the model predictions are presented for the sum of all isomers present in the model. Moreover, no data for the ionization of any $\mathrm{C}_{5} \mathrm{H}_{10} \mathrm{OH}$ radical is available and the ionization threshold must be estimated (10.7 eV, for best fit) within the data evaluation process. Consequently, the experimental uncertainty may exceed a factor 4 in this case. Taken this in account, the peak positions and the concentrations are in remarkable agreement with the modeled profiles for the three investigated pentanols.

In detail, the 1-pentanol destruction pathways involve the $\alpha-, \beta-, \gamma-, \delta-\mathrm{C}_{5} \mathrm{H}_{10} \mathrm{OH}$ radicals with the primary $\varepsilon-\mathrm{C}_{5} \mathrm{H}_{10} \mathrm{OH}$ radical produced at very low rates. According to the reaction pathway analysis, the abstraction of the $\alpha-\mathrm{H}$-atom is the largest contributor. This is in agreement with the results of Tang et al. [14] and with bond strength calculations by Sarathy et al. [16], identifying the $\alpha-\mathrm{C}-\mathrm{H}$ bond as the weakest and the $\varepsilon-\mathrm{C}-\mathrm{H}$ as the strongest bond. $\mathrm{H}$-abstraction from 2-pentanol is considered at the $\alpha-, \beta$ - and $\gamma$-site shown in Fig. 4. Similar to 1-pentanol, abstraction of the $\alpha-\mathrm{H}$-atom is favored. According to the reaction path analysis, the $\alpha-\mathrm{C}_{5} \mathrm{H}_{10} \mathrm{OH}$ radical is formed in a similar fraction as found for the 1-pentanol i.e. its formation is disproportionately preferred since 2-pentanol provides a single $\alpha-\mathrm{H}$-atom. For the 3-pentanol molecule, only 3 types of $\mathrm{C}-\mathrm{H}$ bonds are present and $\mathrm{H}$-abstraction reactions from $\alpha-, \beta$ - and $\gamma$-sites are considered. Note, that the $\gamma-\mathrm{C}_{5} \mathrm{H}_{10} \mathrm{OH}$ radical is the only primary fuel radical considered in the presented reaction pathway diagram because of its fast formation. This finding is consistent when the enhanced statistical presence of these $\mathrm{H}$ atom type (appears six times) in 3-pentanol is considered. However, its formation probability is nevertheless significantly below those of the secondary radicals formed by abstraction at the $\alpha$ - and $\beta$-carbon.

Since no direct experimental determination of the branching ratio between the fuel radicals can be obtained, the remainder of the discussion will focus on the decay products of the individual pentanoyl $\left(\mathrm{C}_{5} \mathrm{H}_{10} \mathrm{OH}\right)$ radicals. The experimental and calculated intermediate species profiles of these products from primary reaction channels are summarized and compared in the figures below. Note that the remainder of the discussion is not strictly 
following the destruction pathways of one individual pentanol or pentanoyl radical, but will focus on the relative branching ratios of the identified important species. The experimental data will be compared to the model data for each identified species to analyze the overall model performance for predictive capability of all three fuels.

\subsubsection{C5 compounds}

Following the major paths of the $\mathrm{C}_{5} \mathrm{H}_{10} \mathrm{OH}$ radicals in the reaction pathway analysis in Fig. 4, $\mathrm{C}_{5} \mathrm{H}_{10} \mathrm{O}$ species are formed dominantly in all cases. They produce the appropriate aldehyde or ketone through a fast scission of the hydroxyl-H as primary decomposition channel when $\mathrm{H}$ abstraction in $\alpha$-position takes place. Furthermore the respective unsaturated pentanol may be formed via $\beta$-scission of a C-H bond.

For the 1-pentanol, the model predicts the reaction from $\alpha-1-\mathrm{C}_{5} \mathrm{H}_{10} \mathrm{OH}$ to form the aldehyde (pentanal) being the dominant pathway. The unsaturated pent-2-en-1-ol and pent-3-en-1-ol as products of $\beta-, \gamma-$ and $\delta-1-\mathrm{C}_{5} \mathrm{H}_{10} \mathrm{OH}$ decomposition are formed alongside the enol structure (pent-1-en-1-ol). A further comparison to the model presented by Sarathy et al. [19], shown in the supplemental material, yields identical major reaction pathways.

A similar pathway is observed for the 2-pentanol destruction with the formation of 2pentanone from the $\alpha-2-\mathrm{C}_{5} \mathrm{H}_{10} \mathrm{OH}$ being the major contributor of the $\mathrm{C}_{5} \mathrm{H}_{10} \mathrm{O}$ isomer. This ketone mainly isomerizes to the subsequent enol pent-2-en-2-ol via formation of a resonance stabilized $\mathrm{C}_{5} \mathrm{H}_{9} \mathrm{O}$ radical by $\mathrm{H}$-abstraction reaction and is subsequently transformed by $\mathrm{H}$ addition to the corresponding enol structure: pent-2-en-2-ol. Note that this reaction channel is a reverse keto-enol tautomerization reaction sequence. Typically the keto structure is favored and this direction is unique for the heavy hydrogen rich conditions presented in this study. An additional enol formation channel is found from $\mathrm{H}$-abstraction of the $\beta-2-\mathrm{C}_{5} \mathrm{H}_{10} \mathrm{OH}$. Similar to the 1-pentanol, two more unsaturated pentenols are formed from the $\beta$ - and $\gamma-2-\mathrm{C}_{5} \mathrm{H}_{10} \mathrm{OH}$ likewise with minor contributions.

Finally, consistent behavior can be reported for the 3-pentanol destruction with the formation of 3-pentanone being the major isomeric species from the $\alpha-3-\mathrm{C}_{5} \mathrm{H}_{10} \mathrm{OH}$ decomposition channel. Reaction to the pent-2-en-3-ol is present as well as one of the major pathways. Again the reverse keto-enol reaction sequence is found to be an active source of pent-2-en-3-ol at these conditions. The formation of the unsaturated pent-1-en-3-ol from the $\beta-$ and $\gamma-3-\mathrm{C}_{5} \mathrm{H}_{10} \mathrm{OH}$ is only a minor path to be found in the model prediction. 
The mole fractions of the $\mathrm{C}_{5} \mathrm{H}_{10} \mathrm{O}$ isomers are presented with experimental data in Fig. 5 (top, right). The model prediction indicates for each pentanol at least three relevant contributing isomeric species for the $\mathrm{C}_{5} \mathrm{H}_{10} \mathrm{O}$ signal with 2- or 3-pentanone or in case for the 1-pentanol, the pentanal respectively, as major contributors. Since the different isomers cannot be resolved in the experimental data here, the predicted sum of all $\mathrm{C}_{5} \mathrm{H}_{10} \mathrm{O}$ isomers must be compared to the model result. Experimental calibration is guided by the predicted major contributing isomers. The ratio of the peak concentrations are captured well for the three pentanols starting with 1-pentanol being the lowest and 2- and 3-pentanol with the highest peak concentration. Profile shape is matched quite well also including position. However, the predicted profiles are around $1 \mathrm{~mm}$ closer to the burner surface. Note, that the predicted profiles are not shifted and concentrations are within the experimental error tolerance for the 2- and 3-pentanol.

In the next step of the destruction pathway, the mole fractions of $\mathrm{C}_{5} \mathrm{H}_{10}$ species are compared to the experimental data in Fig. 6 (bottom, left). While the 2-pentanol major destruction pathway does not include this species, it serves a key role in the 3-pentanol destruction channel as 2-pentene originating from the unsaturated alcohols pent-2-en-3-ol and pent-1-en3-ol. A minor role is found in the 1-pentanol flame where a reaction channel from pent-2-en1-ol to 1-pentene is active. All of these reaction channels are initiated by $\mathrm{H}$-addition to the double bond and subsequent scission of the respective C-O bond.

An experimental pentene profile was only obtained in the 3-pentanol doped flame where the peak position is matched quite well, while peak concentration is overpredicted by a factor of 4 which somewhat exceeds the error limits associated with the RICS calibration of 2-pentene. $\mathrm{C}_{5} \mathrm{H}_{10}$ was not detected in the 1- and 2-pentanol doped flames. However, fragmentation of the parent ion of all pentanols was observed even at the applied soft ionization conditions. Consequently the $\mathrm{m} / \mathrm{z}=70$ signal in all three flames are corrected and only at the 3-pentanol flame some signal was left. It should be noted that this significantly increases the detection limit of $\mathrm{C}_{5} \mathrm{H}_{10}$.

Following the reaction pathway, the next C5-hydrocarbon species identified in the major destruction pathway are four different $\mathrm{C}_{5} \mathrm{H}_{8} \mathrm{O}$ species: propyl ketene (pent-1-enal) and pent-2enal for the 1-pentanol doped flame, pent-3-en-2-one for the 2-pentanol flame and pent-1-en3-one for the 3-pentanol flame. The model proposes the formation of the propyl ketene from two equivalent channels, both starting from the pentanal. Radicals (not shown in Fig. 4) are 
formed by abstraction from the $\alpha$-site ( $\alpha$-pentanalyl radical) in the first place and the $\beta$-site ( $\beta$-pentanalyl) in the second case. Unfortunately, due to the challenging conditions on radical detection, no experimental data can be reported for the $\mathrm{C}_{5} \mathrm{H}_{9} \mathrm{O}$ species. The second $\mathrm{C}_{5} \mathrm{H}_{8} \mathrm{O}$ species formed in the 1-pentanol destruction pathway is pent-2-enal formed directly from the enol species (pent-1-en-1-ol and pent-2-en-1-ol).

In comparison to the mechanism of Sarathy et al., a noticeable difference is found. Here, pentanal reacts by $\mathrm{H}$-abstraction reaction to form $\mathrm{C}_{5} \mathrm{H}_{9} \mathrm{O}$ radicals ( $\alpha$-pentanalyl, $\beta$ pentanalyl). A stable $\mathrm{C}_{5} \mathrm{H}_{8} \mathrm{O}$ intermediate is formed from $\mathrm{H}$-abstraction of $\mathrm{C}_{5} \mathrm{H}_{9} \mathrm{O}$ radicals. The Sarathy et al. mechanism does not include the consumption path of $\mathrm{C}_{5} \mathrm{H}_{9} \mathrm{O}$ to $\mathrm{C}_{5} \mathrm{H}_{8} \mathrm{O}$. Therefore, the concentration of $\mathrm{C}_{5} \mathrm{H}_{9} \mathrm{O}$ is overpredicted in their mechanism by an order and likewise, the $\mathrm{C}_{5} \mathrm{H}_{8} \mathrm{O}$ concentration is underpredicted by a factor of four. Despite this minimal difference in the reactions pathways, the mechanisms are found to be comparable, since the major path of 1-pentanal destruction leads to the formation of 1-butyl $\left(\mathrm{C}_{4} \mathrm{H}_{9}\right)$ in both cases. Additional figures on the comparison of the major and intermediate species are presented in the supplemental material.

In case of the 2-pentanol and 3-pentanol destruction, the unsaturated ketones (pent-3-en-2-one and pent-1-en-3-one, respectively) are formed from various $\mathrm{C}_{5} \mathrm{H}_{10} \mathrm{O}$ precursors. Reactions are subsequent $\mathrm{H}$-abstraction and $\beta$-scission channels, if precursors are ketones or ally hydroxyl structures. Enols may decompose by the following sequence initiated by hydroxyl-Habstraction:

$\mathrm{R}-\mathrm{CH}_{2}-\mathrm{CH}=\mathrm{C}(\mathrm{OH})-\mathrm{R}^{\prime}-\mathrm{H} \rightarrow \mathrm{R}-\mathrm{CH}_{2}-\mathrm{CH}=\mathrm{C}(\mathrm{O})-\mathrm{R}^{\prime} \rightarrow \mathrm{R}-\mathrm{CH}=\mathrm{CH}-\mathrm{C}(=\mathrm{O})-\mathrm{R}^{\prime}+\mathrm{H}$

This otherwise unusual reaction path is found several times in the presented destruction pathways for all three pentanols.

Experimental data for the $\mathrm{C}_{5} \mathrm{H}_{8} \mathrm{O}$ species is shown with modeled profiles in Fig. 5 (bottom right). Again, calibration factors are determined according to the predicted primary isomer i.e. propyl ketene for 1-pentanol, pent-3-en-2-one for 2-pentanol and pent-1-en-3-one for 3-pentanol. Note, that no data for the ionization threshold for propyl ketene is available and thus the value was estimated $(\mathrm{IP}=8.7 \mathrm{eV})$ according to the homologous series $\left(\mathrm{IP}_{\text {ketene }}=9.6\right.$; $\mathrm{IP}_{\text {methyl ketene }}=9.0 \mathrm{eV}$; $\mathrm{IP}_{\text {ethyl ketene }}=8.8 \mathrm{eV}$ [34]). Peak position and profile shape of $\mathrm{C}_{5} \mathrm{H}_{8} \mathrm{O}$ are in good agreement for all pentanols. Mole fraction ratios between the flames are also well reproduced, peak concentrations are overpredicted by a factor of 2 for the 1- and 2-pentanol 
case. However, this is still very well within the uncertainty and can be stated as a good agreement. For the pent-1-en-3-one in the 3-pentanol destruction channel, the overprediction by a factor of 6 is noteworthy.

In compliance with the overprediction of the 2-pentene above, the experimental data could indicate an alternative destruction channel as predicted by the RMG model. However, other factors like fragmentation or sampling effects cannot be ruled out completely. Despite these overpredictions, the overall ratio for all three pentanols is yielded by the model quite satisfactory.

\subsubsection{C4 compounds}

Regarding the $\mathrm{C}_{4} \mathrm{H}_{8} \mathrm{O}$ species, three distinct species are found in the destruction pathways. The destruction channel for the 1-pentanol flame enables the formation of the but-3-en-1-ol through $\mathrm{H}$-addition to the precursors double bond and subsequent $\beta$-scission of the terminal C-C bond, while but-2-en-2-ol is the dominating $\mathrm{C}_{4} \mathrm{H}_{8} \mathrm{O}$ species in the 2-pentanol destruction route. In the 3-pentanol destruction, but-1-en-2-ol is the major contributor to be found and formed from the pent-1-en-3-one. This reaction step follows a three step process where two intermediates pent-1-en-3-one-3-yl radical and pent-2-en-3-ol are subsequently formed by Haddition reactions leading finally to the formation of but-1-en-2-ol and $\mathrm{CH}_{3}$. The comparison of the $\mathrm{C}_{4} \mathrm{H}_{8} \mathrm{O}$ species in Fig. 6 (left) shows slight underprediction by a factor of 2 in the 1pentanol flame (but-3-en-1-ol) and is therefore only slightly above the uncertainty range of the experiment. Peak position is predicted very well, with a slight shift of $0.5 \mathrm{~mm}$ away from the burner surface. The peak position of the but-2-en-2-ol as major contributor in the 2pentanol case is predicted a little too early, while the predicted peak mole fractions are in good agreement with the experimental results. The mole fraction of the but-1-en-2-ol is underpredicted by a factor of 2 , but the peak position can be predicted quite well by the simulations.

Finally, Fig. 6 gives a comparison of a central key species in the destruction paths: $\mathrm{C}_{4} \mathrm{H}_{8}$ or 1butene identified as major component by the model in all flames. Most major destruction channels join here for further decomposition to smaller hydrocarbons. Figure 6 (right) shows excellent agreement for the ratio of the three fuels. Still reasonable agreement of peak position and shape can be stated as well. Mole fractions are overpredicted by a factor of 3. It is worth mentioning that 1-butene was calibrated by direct cold gas measurement and thus the prediction is clearly out of the experimental error tolerance ( 20\%) in this particular case. 


\subsection{Further combustion intermediates}

The remainder of the discussion will follow the relevant C3-hydrocarbon species to the C1hydrocarbons that are involved in numerous combustion reactions. A validation of specific reaction pathways is therefore not possible, so trends and ratios for individual species are presented and discussed here. Figure 7 shows the C3-hydrocarbon species propanal/acetone $\left(\mathrm{C}_{3} \mathrm{H}_{6} \mathrm{O}\right)$, propene $\left(\mathrm{C}_{3} \mathrm{H}_{6}\right)$, propyl $\left(\mathrm{C}_{3} \mathrm{H}_{7}\right)$ and propane $\left(\mathrm{C}_{3} \mathrm{H}_{8}\right)$.

For the elemental composition $\mathrm{C}_{3} \mathrm{H}_{6} \mathrm{O}$, several plausible isomers are existent. Typically, a strong dependence of the dominating isomer on the fuel structure is found, when isomer resolving experiments are applied. For propanol flames Li et al. [67] and Kasper et al. [68] have independently measured propanal as major $\mathrm{C}_{3} \mathrm{H}_{6} \mathrm{O}$ isomer in 1-propanol combustion while acetone was dominating the 2-propanol flame. Both studies have additionally detected varying minor isomers including the enol structures. Isomeric butanol flames [28] exhibit allyl alcohol and propanal (1-butanol flame), acetone (2-butanol flame) as well as propanal and 1propenol (iso-butanol flame) as major $\mathrm{C}_{3} \mathrm{H}_{6} \mathrm{O}$ isomers. However, the respective butanol model [37] does not reproduce these findings in all detail.

The present model predicts acetone as major isomer in the 2-pentanol flame, propanal for the 1-pentanol flame and a similar concentration of both isomers for the 3-pentanol flame. Due to the varying isomer composition, we have calibrated $\mathrm{C}_{3} \mathrm{H}_{6} \mathrm{O}$ consequently as propanal, which is predicted in appreciable concentrations for all fuels. Considering the large number of isomers, the quantitative agreement for $\mathrm{C}_{3} \mathrm{H}_{6} \mathrm{O}$ can still be stated as sufficient. A significant underprediction of the mole fraction in 1-pentanol, however, is found alongside with a downstream position shift of approximately $2 \mathrm{~mm}$.

Propene is in very good agreement for mole fraction of the 1- and 2-pentanol, while a slight overprediction for the 3-pentanol by a factor of 2 is observed. Peak position and profile shape are in good agreement as well. Taken into account that the detection and quantification of radicals is always a challenging task, good agreement can be reported in peak position and mole fraction. Finally, propane $\left(\mathrm{C}_{3} \mathrm{H}_{8}\right)$ shows peak maxima at $4.5 \mathrm{~mm}$ in the experiment, which is in very good agreement for the 1-pentanol flame. Mole fractions are in worse agreement for the 2- and 3-pentanol flame with an overprediction of a factor of 2 . Note, that propene and propane are calibrated directly by cold gas measurements resulting in high confidence of the absolute experimental mole fraction values. 
The C2-hydrocarbon species ethylene $\left(\mathrm{C}_{2} \mathrm{H}_{4}\right)$, ethyl $\left(\mathrm{C}_{2} \mathrm{H}_{5}\right)$ radical, ethane $\left(\mathrm{C}_{2} \mathrm{H}_{6}\right)$ and ketene $\left(\mathrm{C}_{2} \mathrm{H}_{2} \mathrm{O}\right)$ are shown in Fig. 8. Ethylene, directly calibrated, is underestimated by a factor of 2, while peak position and profile are in reasonable agreement. Ethyl on the other hand is in good agreement for the concentration although being a radical species. Mole fractions are matched by a factor of 2, while peak positions are matched satisfactorily. The same slight shifts are observed for ethane, also directly calibrated, with very good agreement in profile shapes and concentrations.

Finally, ketene has the highest mole fraction for the 2-pentanol that is only overpredicted by the model of a factor 2. Therefore, good agreement can be reported as well as for peak position and profile shape. For the 1-pentanol flame an underprediction of a factor of 2 is found, while for the 3-pentanol a slight overprediction of the mole fraction is presented. Peak position is for both predictions a little too late, but very well within the expectations.

Further mole fraction profiles of the important smaller combustion intermediates methane $\left(\mathrm{CH}_{4}\right)$ and formaldehyde $\left(\mathrm{CH}_{2} \mathrm{O}\right)$ are presented in Fig. 9. Methane is calibrated by direct reference measurements, while formaldehyde is evaluated by convolution of the literature ionization cross section. Methane is in good agreement with the slightly overpredicted model results for all three pentanols. Peak positions differ by $1 \mathrm{~mm}$. Note, that the slightly bimodal distribution in the experimental formaldehyde profile is not present in the modeled data. Reasons for the deviation in the first peak maximum at $3 \mathrm{~mm}$ could be some underestimated or missing reactions in the model; however, ion fragmentation in the experiment cannot be dismissed completely as the fragmentation pattern from various parent ions like the $\mathrm{C}_{2} \mathrm{H}_{10} \mathrm{O}$ or $\mathrm{C}_{5} \mathrm{H}_{8} \mathrm{O}$ species are not known. $\mathrm{CH}_{2} \mathrm{O}$ would be a plausible fragment for some of the predicted species. Taken this into account, reasonable agreement can be also reported for formaldehyde in general.

\subsection{Oxygenated species}

Interestingly, relatively strong signals above the fuel signal at $\mathrm{m} / \mathrm{z}=88.09$ were found with a typical intermediate profile shape at $\mathrm{m} / \mathrm{z}=102$ and at $\mathrm{m} / \mathrm{z}=100$ for all three pentanols. The peak maximum is around $4 \mathrm{~mm}$ and the signal decay follows the fuel signal closely. Due to the high mass resolution of the MBMS system, the elemental composition can be identified as $\mathrm{C}_{5} \mathrm{H}_{10} \mathrm{O}_{2}(\mathrm{~m} / \mathrm{z}=102)$ and $\mathrm{C}_{5} \mathrm{H}_{8} \mathrm{O}_{2}$ respectively $(\mathrm{m} / \mathrm{z}=100)$. Concentrations of those double oxygenated species are in the order of $10^{-5}$ (when an ionization threshold of $10 \mathrm{eV}$ is assumed) for both signals. A structural analysis of these compounds is admitting beyond the 
present work, however, taken the fairly low temperature of the hydrogen system into account, species like peroxides or cyclic ethers could be very likely. This is underlined recently by the findings of Seidel et al. [65].

Furthermore, similar to the report of Lucassen et al. [20], signals at $\mathrm{m} / \mathrm{z}=74.04$ were found in the present flames with concentrations in the order of $10^{-5}$. The high mass resolution confirms the finding of neither $\mathrm{C}_{6} \mathrm{H}_{2}$ nor the butanol isomer $\mathrm{C}_{4} \mathrm{H}_{10} \mathrm{O}$, but $\mathrm{C}_{3} \mathrm{H}_{6} \mathrm{O}_{2}$ at $\mathrm{m} / \mathrm{z}=74$ with an intermediate profile. The same can be reported here at $\mathrm{m} / \mathrm{z}=60.06$ for the clearly separated signal of $\mathrm{C}_{2} \mathrm{H}_{4} \mathrm{O}_{2}$, again with intermediate profile shape. While the species listed above confirm the findings of Lucassen et al. [20] throughout. Another separated signal was detected beside the fuel signal at $\mathrm{m} / \mathrm{z}=88.05$ and can be assigned for a fourth double oxygenated species: $\mathrm{C}_{4} \mathrm{H}_{8} \mathrm{O}_{2}$ with intermediate profile and concentrations a magnitude lower than the other detected signals for the double oxygenated species. Many of those oxygenated species mentioned above are not yet present in the combustion chemistry models and further studies are needed to investigate their structure and relevance. Moreover, powerful techniques such as PEPICO are needed to overcome this challenge [23, 69].

\section{Summary and conclusions}

We present the first comparative flame study for 1-, 2- and 3-pentanol with new experimental speciation data and kinetic modeling. The combustion chemistry of all three straight-chain pentanol isomers was experimentally investigated in a low-pressure hydrogen base flame doped with 1-, 2-, or 3-pentanol. New quantitative species profiles for up to 27 species including the pentanoyl radicals are presented and discussed. The dataset, available for download, is supplemented by disturbed temperature profiles and additional data on two branched pentanol isomers (3-methyl-1-pentanol and 3-methyl-2-pentanol).

A new detailed reaction mechanism covering all straight-chain pentanols in one model was constructed and presented here. This model is based on the rule-based reaction model generator software (RMG) and tested against new experimental speciation data and existing literature data. The model was found to reproduce the general flame structure (i.e. the major species profiles) of the doped hydrogen flames as well as crucial intermediate species predictions with satisfactory quality for all three pentanols. The comparisons with experimental measurements are presented without any shift.

Furthermore, the detailed speciation information is used to examine important reaction pathways. Regarding the reaction networks, a special emphasis was placed on the initial fuel 
destruction pathways down to C3-hydrocarbon species. Finally, new species found by the EIMBMS experiment were reported, which are likely to be doubled oxygenated species.

\section{Acknowledgements}

The authors are grateful to Prof. Katharina Kohse-Höinghaus for access to her EI-MBMS flame spectrometer in Bielefeld and for helpful discussions. T. Mosbach and S. Werner are gratefully acknowledged for supporting the temperature measurements. Funding by the Helmholtz Association is acknowledged by P.O. and M.K. as well as from the DLR Centerof-Excellence “Alternative Fuels”. T.K. gratefully acknowledges Helmholtz Post-doc Program for research funding.

\section{References}

[1] J.M. Bergthorson, M.J. Thomson, Renew. Sustain. Energy Rev., 42 (2015) 1393-1417.

[2] E.G. Giakoumis, C.D. Rakopoulos, A.M. Dimaratos, D.C. Rakopoulos, Progr. Energy Combust. Sci., 38 (2012) 691-715.

[3] P.S. Nigam, A. Singh, Progr. Energy Combust. Sci., 37 (2011) 52-68.

[4] K. Kohse-Höinghaus, P. Oßwald, T.A. Cool, T. Kasper, N. Hansen, F. Qi, C.K. Westbrook, P.R. Westmoreland, Angew. Chem., 49 (2010) 3572-3597.

[5] S.M. Sarathy, P. Oßwwald, N. Hansen, K. Kohse-Höinghaus, Progr. Energy Combust. Sci., 44 (2014) 40-102.

[6] A.F. Cann, J.C. Liao, Appl. Microbiol. Biotechnol., 85 (2010) 893-899.

[7] P.P. Peralta-Yahya, J.D. Keasling, Biotechnol. J., 5 (2010) 147-162.

[8] Y. Yang, J.E. Dec, N. Dronniou, B. Simmons, SAE Int. J. Fuels Lubr., 3 (2010) 725-741.

[9] T. Tsujimura, W.J. Pitz, F. Gillespie, H.J. Curran, B.W. Weber, Y. Zhang, C.J. Sung, Energ. Fuel, 26 (2012) 4871-4886.

[10] J. Campos-Fernandez, J.M. Arnal, J. Gomez, N. Lacalle, M.P. Dorado, Fuel, 107 (2013) 866-872. [11] L. Wei, C.S. Cheung, Z. Huang, Energy, 70 (2014) 172-180.

[12] C. Togbé, F. Halter, F. Foucher, C. Mounaim-Rousselle, P. Dagaut, Proc. Combust. Inst., 33 (2011) 367-374.

[13] G. Dayma, C. Togbé, P. Dagaut, Energ. Fuel, 25 (2011) 4986-4998.

[14] C. Tang, L. Wei, X. Man, J. Zhang, Z. Huang, C.K. Law, Combust. Flame, 160 (2013) 520-529.

[15] K.A. Heufer, S.M. Sarathy, H.J. Curran, A.C. Davis, C.K. Westbrook, W.J. Pitz, Energ. Fuel, 26 (2012) 6678-6685.

[16] Q. Li, E. Hu, X. Zhang, Y. Cheng, Z. Huang, Energ. Fuel, 27 (2013) 1141-1150.

[17] L. Zhao, L. Ye, F. Zhang, L. Zhang, J. Phys. Chem. A, 116 (2012) 9238-9244.

[18] O. Welz, J. Zador, J.D. Savee, M.Y. Ng, G. Meloni, R.X. Fernandes, L. Sheps, B.A. Simmons,

T.S. Lee, D.L. Osborn, C.A. Taatjes, Phys. Chem. Chem. Phys., 14 (2012) 3112-3127.

[19] S.M. Sarathy, S. Park, B.W. Weber, W. Wang, P.S. Veloo, A.C. Davis, C. Togbé, C.K.

Westbrook, O. Park, G. Dayma, Z. Luo, M.A. Oehlschlaeger, F.N. Egolfopoulos, T. Lu, W.J. Pitz, C.J. Sung, P. Dagaut, Combust. Flame, 160 (2013) 2712-2728.

[20] A. Lucassen, S. Park, N. Hansen, S.M. Sarathy, Proc. Combust. Inst., 35 (2015) 813-820.

[21] X. Zhang, B. Yang, W. Yuan, Z. Cheng, L. Zhang, Y. Li, F. Qi, Proc. Combust. Inst., 35 (2015) 409-417.

[22] Z. Serinyel, C. Togbé, G. Dayma, P. Dagaut, Combust. Flame, 161 (2014) 3003-3013.

[23] P. Oßwald, P. Hemberger, T. Bierkandt, E. Akyildiz, M. Köhler, A. Bodi, T. Gerber, T. Kasper, Rev. Sci. Instrum., 85 (2014) 025101. 
[24] D. Felsmann, K. Moshammer, J. Krüger, A. Lackner, A. Brockhinke, T. Kasper, T. Bierkandt, E. Akyildiz, N. Hansen, A. Lucassen, P. Oßwald, M. Köhler, G.A. Garcia, L. Nahon, P. Hemberger, A. Bodi, T. Gerber, K. Kohse-Höinghaus, Proc. Combust. Inst., 35 (2015) 779-786.

[25] W.H. Green, J.W. Allen, A. Beat, R. Buesser, W. Ashcraft, G.J. Beran, C.A. Class, C. Gao, C.F. Goldsmith, M.R. Harper, A. Jalan, M. Keceli, G.R. Magoon, D.M. Matheu, S.S. Merchant, J.D. Mo, S. Petway, S. Raman, S. Sharma, J. Song, Y. Suleymanov, K.M.V. Geem, J. Wen, R.H. West, A. Wong, H.-W. Wong, Y. P. E, N. Yee, J. Yu, RMG-Reaction Mechanism Generator v4.0.1, http://rmg.sourceforge.net/, (2013).

[26] F. Herrmann, B. Jochim, P. Oßwald, L. Cai, H. Pitsch, K. Kohse-Höinghaus, Combust. Flame, 161 (2014) 384-397.

[27] M. Schenk, L. Leon, K. Moshammer, P. Oßwald, T. Zeuch, L. Seidel, F. Mauss, K. KohseHöinghaus, Combust. Flame, 160 (2013) 487-503.

[28] P. Oßwald, H. Güldenberg, K. Kohse-Höinghaus, B. Yang, T. Yuan, F. Qi, Combust. Flame, 158 (2011) 2-15.

[29] F. Herrmann, P. Oßwald, K. Kohse-Höinghaus, Proc. Combust. Inst., 34 (2013) 771-778.

[30] J. Warnatz, U. Maas, R.W. Dibble, Combustion: Physical and Chemical Fundamentals, Modeling and Simulation, Experiments, Pollutant Formation, Springer, Berlin Heidelberg, 1996.

[31] C. Morley, Gaseq 0.79, a Chemical Equilibrium Program for Windows (2005).

[32] E. Goos, A. Burcat, B. Ruscic, Extended Third Millennium Ideal Gas and Condensed Phase Thermochemical Database for Combustion with Updates from Active Thermochemical Tables,

(2013).

[33] W.L. Fitch, A.D. Sauter, Anal. Chem., 55 (1983) 832-835.

[34] Y.-K. Kim, K.K. Irikura, M.E. Rudd, M.A. Ali, P.M. Stone, J. Chang, J.S. Coursey, R.A.

Dragoset, A.R. Kishore, K.J. Olsen, A.M. Sansonetti, G.G. Wiersma, D.S. Zucker, M.A. Zucker, NIST Standard Reference Database 107: Electron-Impact Cross Section for Ionization and Excitation.

[35] J.C. Biordi, Progr. Energy Combust. Sci., 3 (1977) 151-173.

[36] S.G. Lias, J.E. Bartmess, J.F. Liebman, J.L. Holmes, R.D. Levin, S.A. Kafafi, W.G. Mallard, NIST Chemistry WebBook, NIST Standard Reference Database Number 69, National Institute of Standards and Technology, Gaithersburg MD, 20899, http://webbook.nist.gov, 2015.

[37] S.M. Sarathy, S. Vranckx, K. Yasunaga, M. Mehl, P. Oßwald, W.K. Metcalfe, C.K. Westbrook, W.J. Pitz, K. Kohse-Höinghaus, R.X. Fernandes, H.J. Curran, Combust. Flame, 159 (2012) 20282055.

[38] D. Liu, C. Togbé, L.-S. Tran, D. Felsmann, P. Oßwald, P. Nau, J. Koppmann, A. Lackner, P.A. Glaude, B. Sirjean, R. Fournet, F. Battin-Leclerc, K. Kohse-Höinghaus, Combust. Flame, 161 (2014) 748-765.

[39] L.-S. Tran, C. Togbé, D. Liu, D. Felsmann, P. Oßwald, P.A. Glaude, R. Fournet, B. Sirjean, F. Battin-Leclerc, K. Kohse-Höinghaus, Combust. Flame, 161 (2014) 766-779.

[40] C. Togbé, L.-S. Tran, D. Liu, D. Felsmann, P. Oßwald, P.A. Glaude, B. Sirjean, R. Fournet, F. Battin-Leclerc, K. Kohse-Höinghaus, Combust. Flame, 161 (2014) 780-797.

[41] U. Struckmeier, P. Oßwald, T. Kasper, L. Böhling, M. Heusing, M. Köhler, A. Brockhinke, K. Kohse-Höinghaus, Z. Phys. Chem., 223 (2009) 503-537.

[42] P. Oßwald, K. Kohse-Höinghaus, U. Struckmeier, T. Zeuch, L. Seidel, L. Leon, F. Mauss, Z. Phys. Chem., 225 (2011) 1029-1054.

[43] M. Köhler, K.-P. Geigle, T. Blacha, P. Gerlinger, W. Meier, Combust. Flame, 159 (2012) 26202635.

[44] J. Vandooren, J. Bian, Symp. Combust. Proc., 23 (1991) 341-346.

[45] J.-F. Pauwels, J.V. Volponi, J.A. Miller, Combust. Sci. Technol., 110-111 (1995) 249-276.

[46] A. Lawitzki, I. Plath, W. Stricker, J. Bittner, U. Meier, K. Kohse-Höinghaus, App.l Phys. B, 50 (1990) 513-518.

[47] K.J. Rensberger, J.B. Jeffries, R.A. Copeland, K. Kohse-Höinghaus, M.L. Wise, D.R. Crosley, Appl. Opt., 28 (1989) 3556-3566.

[48] K.J. Rensberger, M.J. Dyer, R.A. Copeland, Appl. Opt., 27 (1988) 3679-3689.

[49] J.V. Volponi, M.C. Branch, Combust. Sci. Technol., 105 (1995) 195-209.

[50] K.H. Eberius, K. Hoyermann, H.G. Wagner, Symp. Combust. Proc., 13 (1971) 713-721. 
[51] R.G. Susnow, A.M. Dean, W.H. Green, P. Peczak, L.J. Broadbelt, J. Phys. Chem. A, 101 (1997) 3731-3740.

[52] A.Y. Chang, J.W. Bozzelli, A.M. Dean, Z. Phys. Chem., 214 (2000) 1533-1568.

[53] S.W. Benson, Thermochemical kinetics: methods for the estimation of thermochemical data and rate parameters, Wiley, 1976.

[54] J. Welty, C.E. Wicks, G.L. Rorrer, R.E. Wilson, Fundamentals of Momentum, Heat and Mass Transfer 5th Edition with Product and Process 3rd Edition Set, John Wiley \& Sons Canada, Limited, 2009.

[55] H. Wang, X. You, A.V. Joshi, S.G. Davis, A. Laskin, F. Egolfopoulos, C.K. Law, USC Mech Version II. High-Temperature Combustion Reaction Model of H2/CO/C1-C4 Compounds, http://ignis.usc.edu/USC_Mech_II.htm, 2007.

[56] M.P. Burke, M. Chaos, Y.G. Ju, F.L. Dryer, S.J. Klippenstein, Int. J. Chem. Kinet., 44 (2012) 444-474.

[57] J. Li, Z. Zhao, A. Kazakov, F.L. Dryer, Int. J. Chem. Kinet., 36 (2004) 566-575.

[58] S.S. Merchant, E.F. Zanoelo, R.L. Speth, M.R. Harper, K.M. Van Geem, W.H. Green, Combust. Flame, 160 (2013) 1907-1929.

[59] S.G. Davis, C.K. Law, Combust. Sci. Technol., 140 (1998) 427-449.

[60] J. Zhang, E. Hu, Z. Zhang, L. Pan, Z. Huang, Energ. Fuel, 27 (2013) 3480-3487.

[61] J.A. Miller, S.J. Klippenstein, J. Phys. Chem. A, 117 (2013) 2718-2727.

[62] X. Gou, J.A. Miller, W. Sun, Y. Ju, http://engine.princeton.edu, (2001).

[63] S.M. Sarathy, M.J. Thomson, C. Togbé, P. Dagaut, F. Halter, C. Mounaim-Rousselle, Combust. Flame, 156 (2009) 852-864.

[64] Chemical WorkBench ${ }^{\circledR} 4.0$, Kintech laboratory, http://www.kintechlab.com/products/chemicalworkbench/, (2013).

[65] L. Seidel, K. Moshammer, X. Wang, T. Zeuch, K. Kohse-Höinghaus, F. Mauss, Combust. Flame, doi:http://dx.doi.org/10.1016/j.combustflame.2015.01.002 (2015).

[66] A.T. Hartlieb, B. Atakan, K. Kohse-Höinghaus, Combust. Flame, 121 (2000) 610-624.

[67] Y. Li, L. Wei, Z. Tian, B. Yang, J. Wang, T. Zhang, F. Qi, Combust. Flame, 152 (2008) 336-359.

[68] T. Kasper, P. Oßwald, U. Struckmeier, K. Kohse-Höinghaus, C.A. Taatjes, J. Wang, T.A. Cool, M.E. Law, A. Morel, P.R. Westmoreland, Combust. Flame, 156 (2009) 1181-1201.

[69] J. Krüger, G.A. Garcia, D. Felsmann, K. Moshammer, A. Lackner, A. Brockhinke, L. Nahon, K. Kohse-Höinghaus, Phys. Chem. Chem. Phys., 16 (2014) 22791-22804. 


\section{Figures}
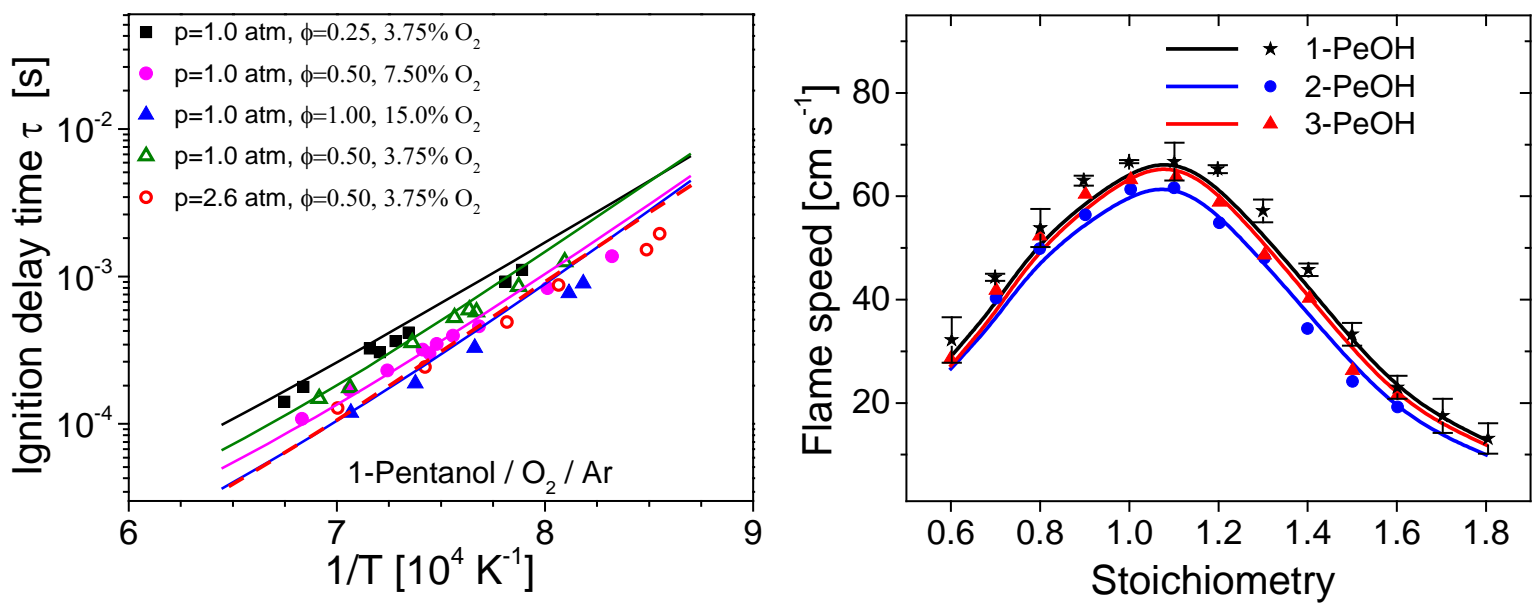

Figure 1: Left: Measured (symbols) [14] and computed (lines) ignition delay times for 1pentanol. Right: Measured (symbols) and computed (lines) laminar flame speed for the three pentanol-air flames measured by Li et al. [16]. The flames are at $433 \mathrm{~K}$ and 1 bar initial pressure.

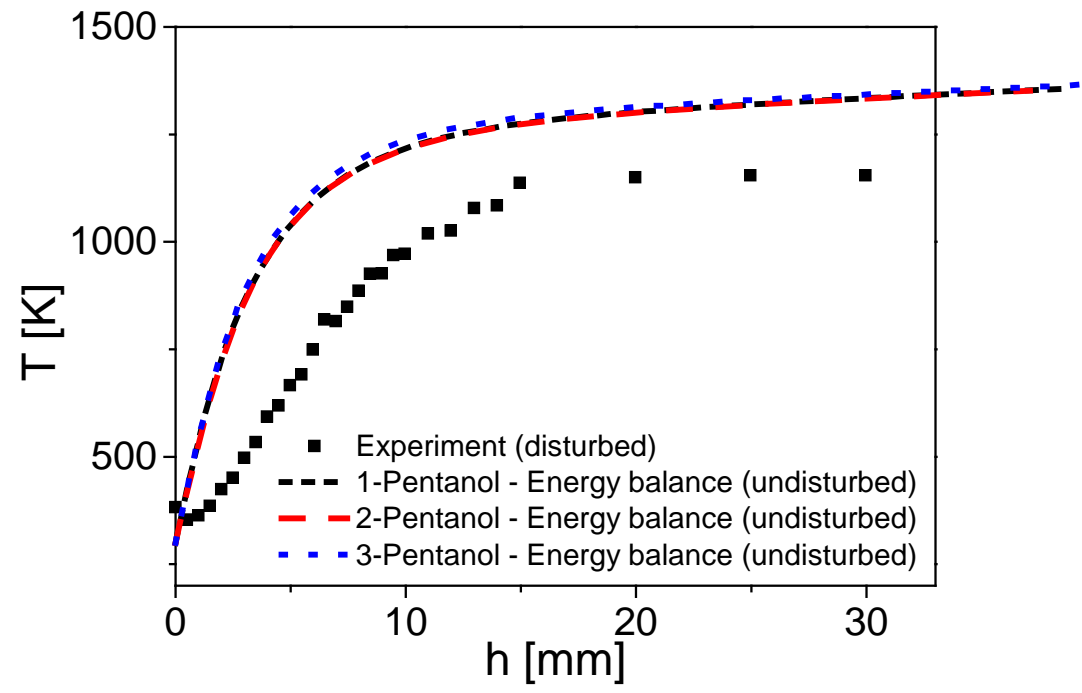

Figure 2: Experimental, disturbed temperature profile (symbols) used as input for presented results compared with the model solution of energy balance calculation (undisturbed profiles). 

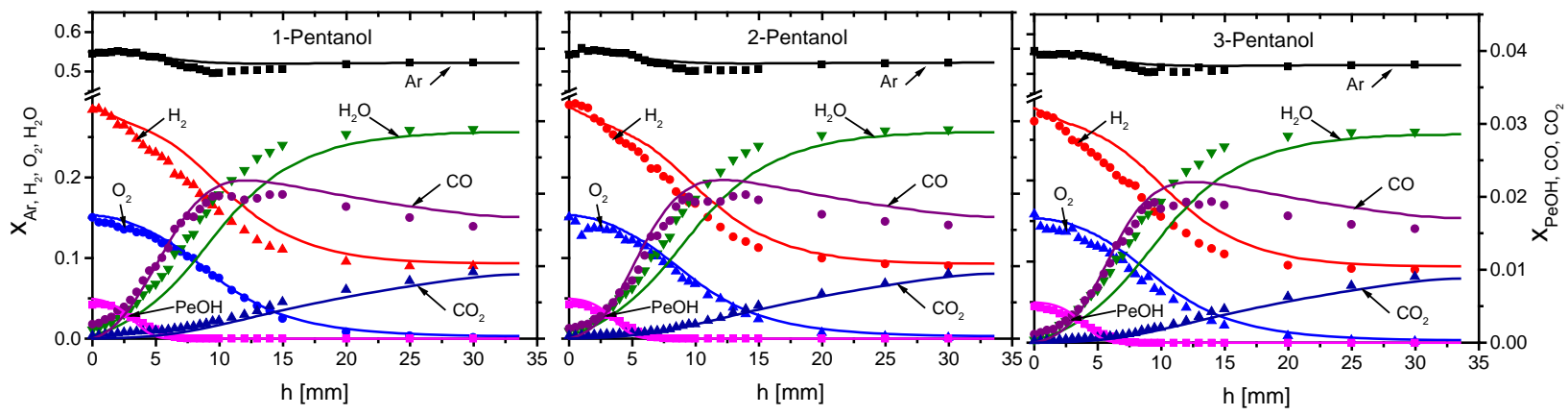

Figure 3: Measured (symbols) and computed (lines) major species mole fraction profiles for the three pentanol flames. $\mathrm{Ar}, \mathrm{H}_{2}, \mathrm{O}_{2}$ and $\mathrm{H}_{2} \mathrm{O}$ right axis; Fuel, $\mathrm{CO}$ and $\mathrm{CO}_{2}$ left axis. 

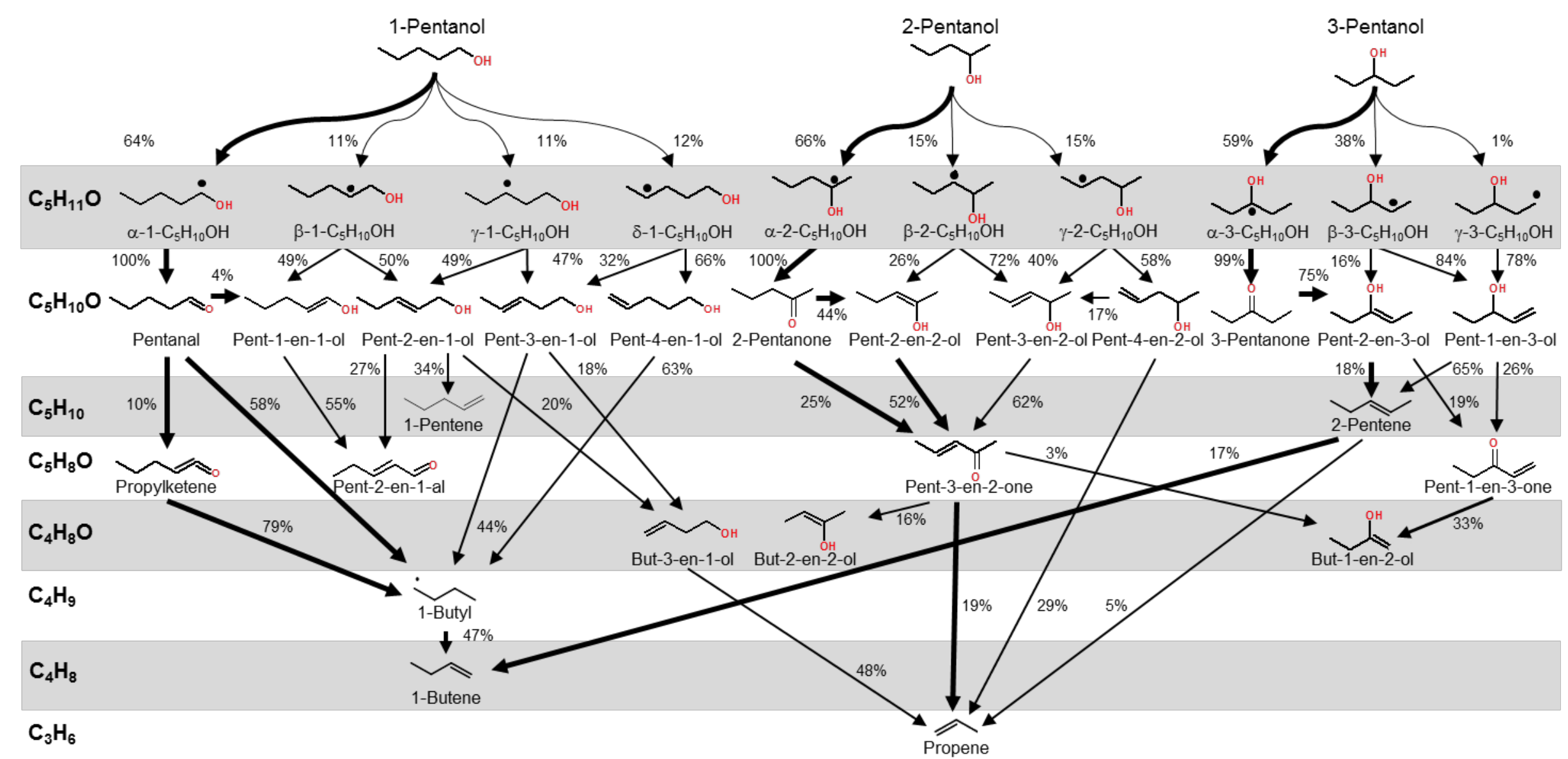

Figure 4: Reaction path diagram for 1-, 2- and 3-pentanol in a $\mathrm{H}_{2} / \mathrm{O}_{2}$ flame at 20 mbar. Note that radical intermediates are neglected; see text for detailed discussion of individual reaction sequences. Only major contributing paths are shown here. The thick line strength indicates the major consumption path, while the thin line strengths show the remainder minor paths (lines not to scale). Percentages indicate decay rate contribution of the given species. 


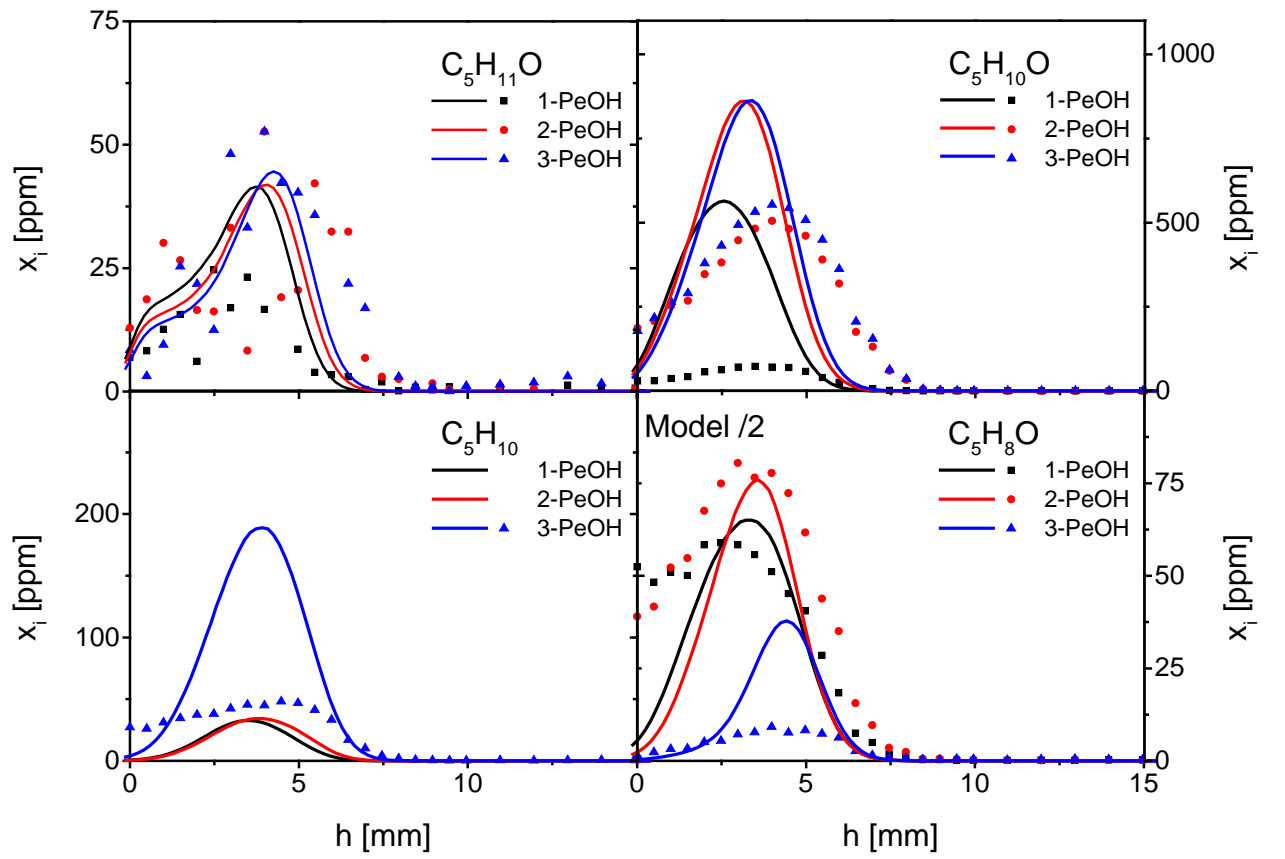

Figure 5: Mole fraction profiles of the $\mathrm{C}_{5} \mathrm{H}_{11} \mathrm{O}$ fuel radicals and $\mathrm{C}_{5} \mathrm{H}_{10} \mathrm{O}, \mathrm{C}_{5} \mathrm{H}_{10}$ and $\mathrm{C}_{5} \mathrm{H}_{8} \mathrm{O}$ intermediates. Symbols represent experimental data and lines represent modeling results. To facilitate comparison of the respective trends, a scaling factor (scaled model data to fit experiment axis) is indicated, when applied.

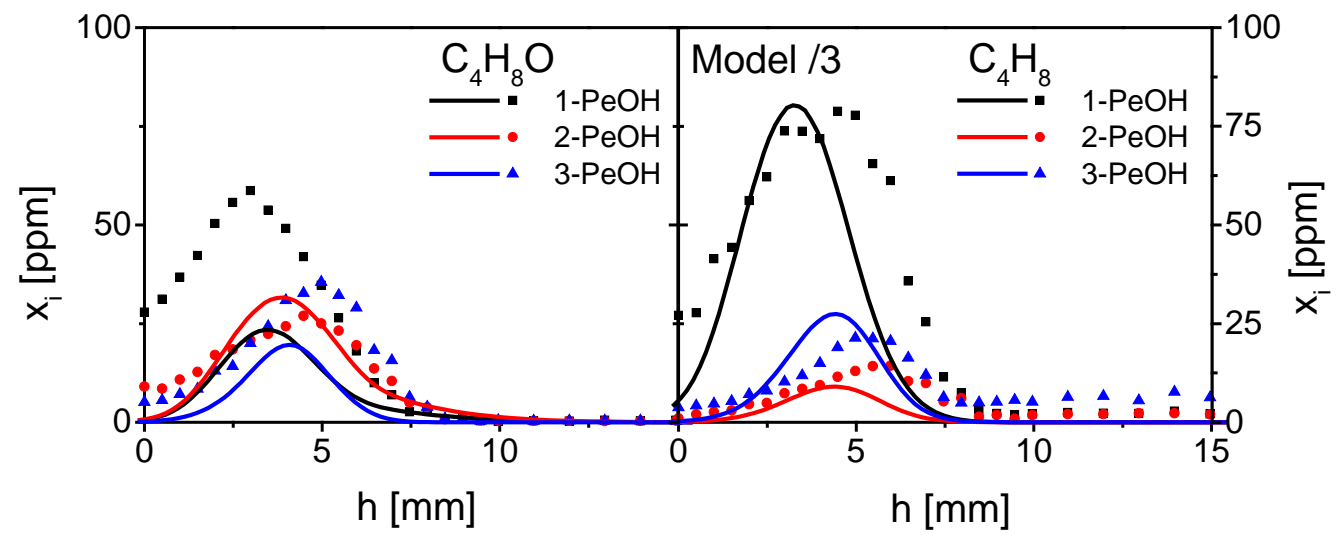

Figure 6: Measured (symbols) and computed (lines) $\mathrm{C}_{4} \mathrm{H}_{8} \mathrm{O}$ and $\mathrm{C}_{4} \mathrm{H}_{8}$ species profiles. To facilitate comparison of the respective trends, a scaling factor (scaled model data to fit experiment axis) is indicated, when applied. 


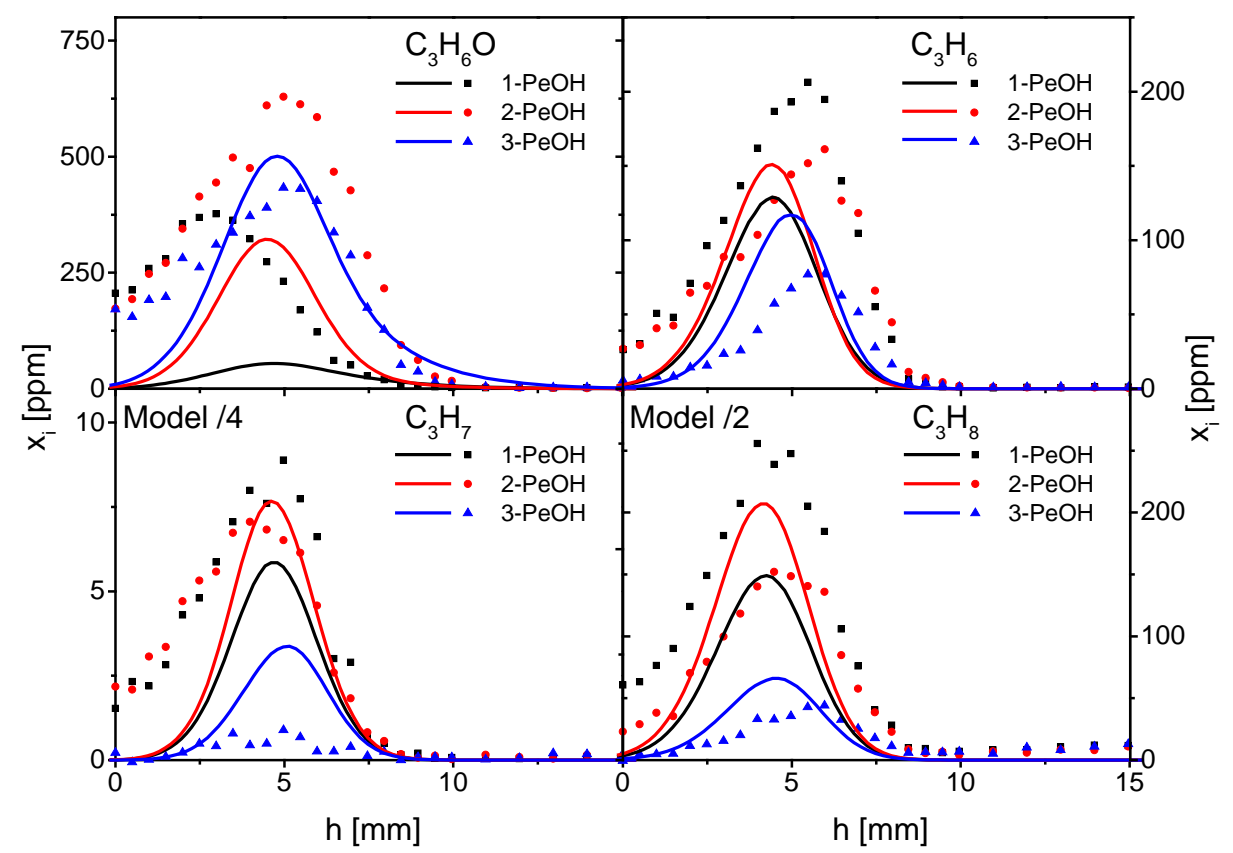

Figure 7: Measured (symbols) and computed (lines) $\mathrm{C}_{3} \mathrm{H}_{6}, \mathrm{C}_{3} \mathrm{H}_{6} \mathrm{O}, \mathrm{C}_{3} \mathrm{H}_{7}$ and $\mathrm{C}_{3} \mathrm{H}_{8}$ species profiles. To facilitate comparison of the respective trends, a scaling factor (scaled model data to fit experiment axis) is indicated, when applied.

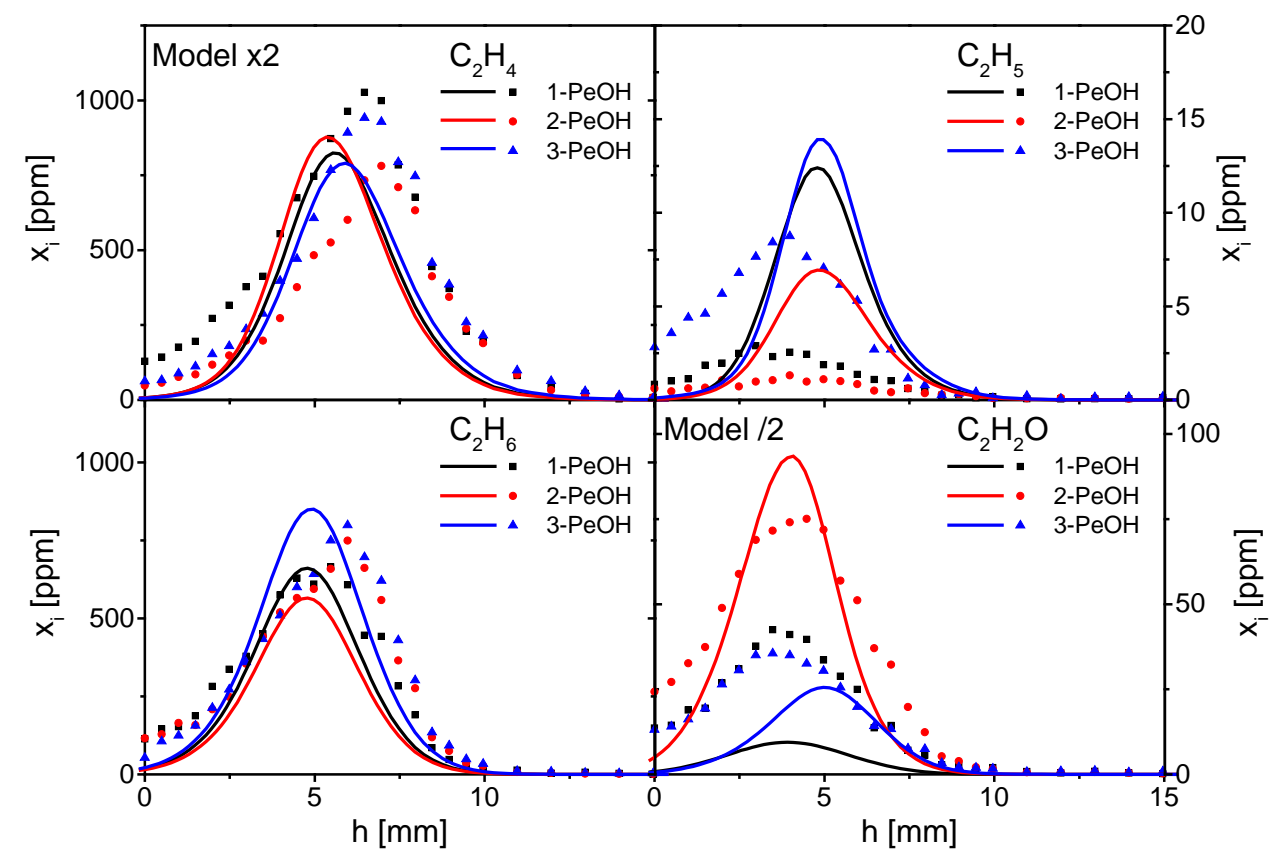

Figure 8: Measured (symbols) and computed (lines) $\mathrm{C}_{2} \mathrm{H}_{4}, \mathrm{C}_{2} \mathrm{H}_{5}, \mathrm{C}_{2} \mathrm{H}_{6}$ and $\mathrm{C}_{2} \mathrm{H}_{2} \mathrm{O}$ species profiles. To facilitate comparison of the respective trends, a scaling factor (scaled model data to fit experiment axis) is indicated, when applied. 


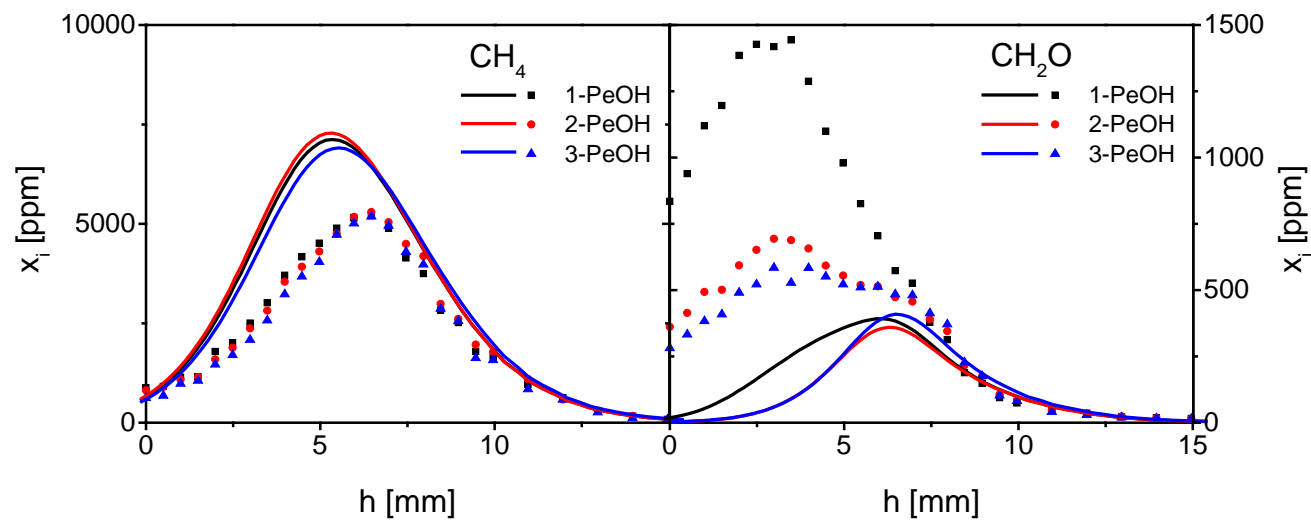

Figure 9: Measured (symbols) and computed (lines) $\mathrm{CH}_{4}$ and $\mathrm{CH}_{2} \mathrm{O}$ species profiles. 
Table 1: Comparison of peak mole fraction $\left(\mathrm{x}_{\max }\right)$ and peak position $(\mathrm{h})$ in mm obtained from experiment and model calculations for the tree pentanol flames. n.e: not evaluable.

\begin{tabular}{|c|c|c|c|c|c|c|c|c|c|c|c|c|c|c|}
\hline \multirow{3}{*}{ Species } & \multirow{3}{*}{ Calibrated as } & \multirow{3}{*}{ Method } & \multicolumn{4}{|c|}{ 1-Pentanol } & \multicolumn{4}{|c|}{ 2-Pentanol } & \multicolumn{4}{|c|}{ 3-Pentanol } \\
\hline & & & \multicolumn{2}{|c|}{ Experiment } & \multicolumn{2}{|l|}{ Model } & \multicolumn{2}{|c|}{ Experiment } & \multicolumn{2}{|l|}{ Model } & \multicolumn{2}{|c|}{ Experiment } & \multicolumn{2}{|l|}{ Model } \\
\hline & & & $x_{\max }$ & $\mathrm{h}$ & $x_{\max }$ & $h$ & $\mathrm{x}_{\max }$ & $h$ & $x_{\max }$ & $h$ & $\mathrm{x}_{\max }$ & $\mathrm{h}$ & $x_{\max }$ & $h$ \\
\hline $\mathrm{CH}_{3}$ & Methyl & $\operatorname{RICS}\left(\mathrm{CH}_{4}\right)$ & $3.6 \times 10^{-05}$ & 5.5 & $8.9 \times 10^{-04}$ & 5.5 & $1.8 \times 10^{-05}$ & 6.0 & $8.6 \times 10^{-04}$ & 5.5 & $2.6 \times 10^{-05}$ & 5.5 & $1.1 \times 10^{-03}$ & 5.7 \\
\hline $\mathrm{CH}_{4}$ & Methane & Direct & $5.2 \times 10^{-03}$ & 6.5 & $7.1 \times 10^{-02}$ & 5.5 & $5.3 \times 10^{-03}$ & 6.5 & $7.3 \times 10^{-03}$ & 5.5 & $5.2 \times 10^{-03}$ & 6.5 & $6.9 \times 10^{-03}$ & 5.7 \\
\hline $\mathrm{CH}_{2} \mathrm{O}$ & Formaldehyde & Conv. & $1.9 \times 10^{-03}$ & 3.5 & $3.9 \times 10^{-04}$ & 6.1 & $8.9 \times 10^{-04}$ & 3.0 & $3.6 \times 10^{-04}$ & 6.4 & $7.5 \times 10^{-04}$ & 3.0 & $4.1 \times 10^{-04}$ & 6.6 \\
\hline $\mathrm{C}_{2} \mathrm{H}_{2}$ & Acetylene & Direct & $2.4 \times 10^{-04}$ & 7.0 & $5.9 \times 10^{-05}$ & 6.8 & $1.7 \times 10^{-04}$ & 6.5 & $5.9 \times 10^{-05}$ & 6.6 & $1.6 \times 10^{-04}$ & 8.0 & $1.9 \times 10^{-04}$ & 6.4 \\
\hline $\mathrm{C}_{2} \mathrm{H}_{4}$ & Ethylene & Direct & $1.0 \times 10^{-03}$ & 6.5 & $4.1 \times 10^{-04}$ & 5.7 & $7.8 \times 10^{-04}$ & 7.0 & $4.4 \times 10^{-04}$ & 5.5 & $9.4 \times 10^{-04}$ & 6.5 & $4.0 \times 10^{-04}$ & 6.0 \\
\hline $\mathrm{C}_{2} \mathrm{H}_{5}$ & Ethyl & $\operatorname{RICS}\left(\mathrm{C}_{2} \mathrm{H}_{6}\right)$ & $2.9 \times 10^{-06}$ & 3.0 & $1.2 \times 10^{-05}$ & 4.9 & $1.3 \times 10^{-06}$ & 4.0 & $6.9 \times 10^{-06}$ & 4.9 & $8.7 \times 10^{-06}$ & 4.0 & $1.4 \times 10^{-05}$ & 5.1 \\
\hline $\mathrm{C}_{2} \mathrm{H}_{6}$ & Ethane & Direct & $6.6 \times 10^{-04}$ & 5.5 & $6.6 \times 10^{-04}$ & 4.9 & $7.5 \times 10^{-04}$ & 6.0 & $5.7 \times 10^{-04}$ & 4.9 & $8.0 \times 10^{-04}$ & 6.0 & $8.5 \times 10^{-04}$ & 5.1 \\
\hline $\mathrm{C}_{2} \mathrm{H}_{2} \mathrm{O}$ & Ketene & Conv. & $4.2 \times 10^{-05}$ & 3.5 & $1.9 \times 10^{-05}$ & 3.9 & $7.5 \times 10^{-05}$ & 4.5 & $1.9 \times 10^{-04}$ & 4.2 & $3.6 \times 10^{-05}$ & 3.5 & $5.1 \times 10^{-05}$ & 5.1 \\
\hline $\mathrm{C}_{2} \mathrm{H}_{4} \mathrm{O}$ & Acetaldehyde & Conv. & $9.8 \times 10^{-04}$ & 3.0 & $6.9 \times 10^{-05}$ & 4.2 & $6.7 \times 10^{-04}$ & 2.5 & $5.1 \times 10^{-04}$ & 4.7 & $4.9 \times 10^{-04}$ & 3.0 & $3.6 \times 10^{-05}$ & 5.1 \\
\hline $\mathrm{C}_{2} \mathrm{H}_{5} \mathrm{O}$ & Ethoxy & $F \& S$ & $1.3 \times 10^{-05}$ & 3.5 & $8.0 \times 10^{-07}$ & 4.4 & n.e. & n.e. & $7.8 \times 10^{-07}$ & 4.9 & $1.0 \times 10^{-05}$ & 3.0 & $9.2 \times 10^{-08}$ & 5.7 \\
\hline $\mathrm{C}_{3} \mathrm{H}_{6}$ & Propene & Direct & $2.1 \times 10^{-04}$ & 5.5 & $1.3 \times 10^{-04}$ & 4.6 & $1.6 \times 10^{-04}$ & 6.0 & $1.5 \times 10^{-04}$ & 4.6 & $7.7 \times 10^{-05}$ & 5.5 & $1.2 \times 10^{-04}$ & 5.1 \\
\hline $\mathrm{C}_{3} \mathrm{H}_{7}$ & Isopropyl & F\&S & $8.9 \times 10^{-06}$ & 5.0 & $2.3 \times 10^{-05}$ & 4.9 & $7.1 \times 10^{-06}$ & 4.0 & $3.1 \times 10^{-05}$ & 4.7 & $8.9 \times 10^{-07}$ & 5.0 & $1.4 \times 10^{-05}$ & 5.3 \\
\hline $\mathrm{C}_{3} \mathrm{H}_{8}$ & Propane & Direct & $2.6 \times 10^{-04}$ & 4.0 & $3.0 \times 10^{-04}$ & 4.4 & $1.5 \times 10^{-04}$ & 4.5 & $4.1 \times 10^{-04}$ & 4.4 & $4.4 \times 10^{-05}$ & 6.0 & $1.3 \times 10^{-04}$ & 4.7 \\
\hline $\mathrm{C}_{3} \mathrm{H}_{6} \mathrm{O}$ & Propanal & F\&S & $3.8 \times 10^{-04}$ & 3.0 & $5.5 \times 10^{-05}$ & 4.7 & $6.3 \times 10^{-04}$ & 5.0 & $3.2 \times 10^{-04}$ & 4.6 & $4.3 \times 10^{-04}$ & 5.0 & $5.0 \times 10^{-04}$ & 4.9 \\
\hline $\mathrm{C}_{4} \mathrm{H}_{8}$ & 1-Butene & Direct & $7.9 \times 10^{-05}$ & 4.5 & $2.4 \times 10^{-04}$ & 3.4 & $1.4 \times 10^{-05}$ & 6.0 & $2.7 \times 10^{-05}$ & 4.6 & $2.1 \times 10^{-05}$ & 5.0 & $8.2 \times 10^{-05}$ & 4.6 \\
\hline $\mathrm{C}_{4} \mathrm{H}_{8} \mathrm{O}$ & see text & $F \& S$ & $5.9 \times 10^{-05}$ & 3.0 & $2.3 \times 10^{-05}$ & 3.7 & $2.7 \times 10^{-05}$ & 4.5 & $3.2 \times 10^{-05}$ & 4.0 & $3.6 \times 10^{-05}$ & 5.0 & $2.0 \times 10^{-05}$ & 4.2 \\
\hline $\mathrm{C}_{5} \mathrm{H}_{10}$ & 2-Pentene & $\mathrm{RICS}\left(\mathrm{nC}_{5} \mathrm{H}_{12}\right)$ & n.e. & n.e. & $3.3 \times 10^{-05}$ & 3.7 & n.e. & n.e. & $3.4 \times 10^{-05}$ & 4.0 & $4.8 \times 10^{-05}$ & 4.5 & $1.9 \times 10^{-04}$ & 4.0 \\
\hline $\mathrm{C}_{5} \mathrm{H}_{8} \mathrm{O}$ & see text & $F \& S$ & $5.9 \times 10^{-05}$ & 2.5 & $1.3 \times 10^{-04}$ & 3.5 & $8.0 \times 10^{-05}$ & 3.0 & $1.5 \times 10^{-04}$ & 3.7 & $9.2 \times 10^{-06}$ & 4.0 & $7.6 \times 10^{-05}$ & 4.6 \\
\hline $\mathrm{C}_{5} \mathrm{H}_{10} \mathrm{O}$ & see text & $F \& S$ & $7.2 \times 10^{-05}$ & 3.5 & $5.6 \times 10^{-04}$ & 2.7 & $5.1 \times 10^{-04}$ & 4.0 & $8.6 \times 10^{-04}$ & 3.4 & $5.5 \times 10^{-04}$ & 4.0 & $8.6 \times 10^{-04}$ & 3.5 \\
\hline $\mathrm{C}_{5} \mathrm{H}_{11} \mathrm{O}$ & Pentanoyl & F\&S (Est. IP) & $2.5 \times 10^{-05}$ & 2.5 & $4.2 \times 10^{-05}$ & 3.9 & $5.3 \times 10^{-05}$ & 4.0 & $4.2 \times 10^{-05}$ & 4.2 & $5.3 \times 10^{-05}$ & 4.0 & $4.5 \times 10^{-05}$ & 4.4 \\
\hline
\end{tabular}


